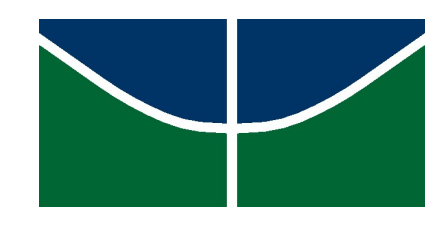

UNIVERSIDADE DE BRASÍLIA

FACULDADE DE AGRONOMIA E MEDICINA VETERINÁRIA

PROGRAMA DE PÓS-GRADUAÇÃO EM SAÚDE ANIMAL

\title{
PREVALÊNCIA E FATORES DE RISCO DA BRUCELOSE BOVINA NO DISTRITO FEDERAL, BRASIL, 2015.
}

JANAINA BITENCOURT LICURGO

DISSERTAÇÃO DE MESTRADO EM SAÚDE ANIMAL

BRASÍLIA/DF

DEZEMBRO/2016 

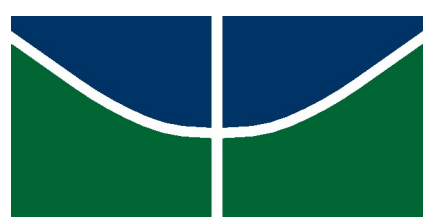

UNIVERSIDADE DE BRASÍLIA

FACULDADE DE AGRONOMIA E MEDICINA VETERINÁRIA

PROGRAMA DE PÓS-GRADUAÇÃO EM SAÚDE ANIMAL

\section{PREVALÊNCIA E FATORES DE RISCO DA BRUCELOSE BOVINA NO DISTRITO FEDERAL, BRASIL, 2015.}

ORIENTADOR: PROF. DR. VÍTOR SALVADOR PICÃO GONÇALVES

DISSERTAÇÃO DE MESTRADO EM SAÚDE ANIMAL

ÁREA DE CONCENTRAÇÃO: MEDICINA PREVENTIVA E PATOLOGIA VETERINÁRIA LINHA DE PESQUISA: EPIDEMIOLOGIA, PREVENÇÃO E CONTROLE DE DOENÇAS DOS ANIMAIS E GESTÃO DOS RISCOS PARA A SAÚDE PÚBLICA

PUBLICAÇÃO: 132/2016

BRASÍLIA/DF

DEZEMBRO/2016 


\section{PREVALÊNCIA E FATORES DE RISCO DA BRUCELOSE BOVINA NO DISTRITO FEDERAL, BRASIL, 2015.}

JANAINA BITENCOURT LICURGO

DISSERTAÇÃO DE MESTRADO SUBMETIDA AO PROGRAMA DE PÓSGRADUACุÃO EM SAÚDE ANIMAL, COMO PARTE DOS REQUISITOS NECESSÁRIOS À OBTENÇÃO DO GRAU DE MESTRE EM SAÚDE ANIMAL.

APROVADA POR:

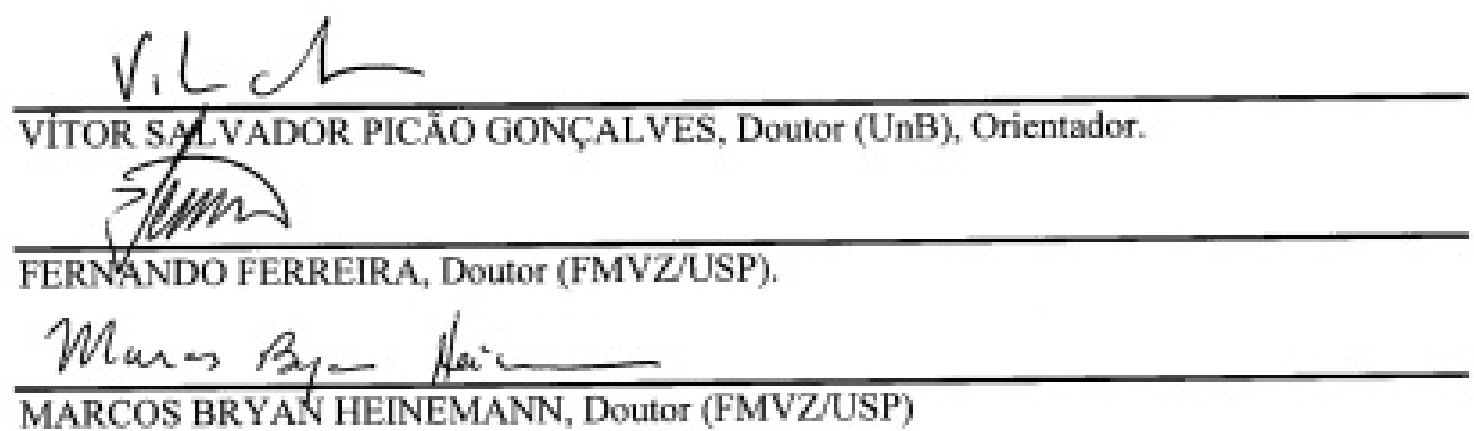

BRASILIA, DF, 09 DE DEZEMBRO DE 2016. 


\title{
REFERÊNCIA BIBLIOGRÁFICA E CATALOGAÇÃO
}

\section{LICURGO, J.B. Prevalência e fatores de risco da brucelose bovina no Distrito Federal,}

Brasil, 2015. Brasília: Faculdade de Agronomia e Medicina Veterinária, Universidade de Brasília, 2016, 54 p. Dissertação de Mestrado.

\begin{abstract}
Documento formal, autorizando reprodução desta dissertação de Mestrado para empréstimo ou comercialização, exclusivamente para fins acadêmicos; foi passado pelo autor à Universidade de Brasília e achase arquivado na secretaria do Programa. O autor reserva para si os outros direitos autorais, de publicação. Nenhuma parte desta dissertação de mestrado pode ser reproduzida sem a autorização por escrito do autor. Citações são estimuladas, desde que citada a fonte.
\end{abstract}

Ficha catalográfica elaborada automaticamente, com os dados fornecidos pelo(a) autor(a)

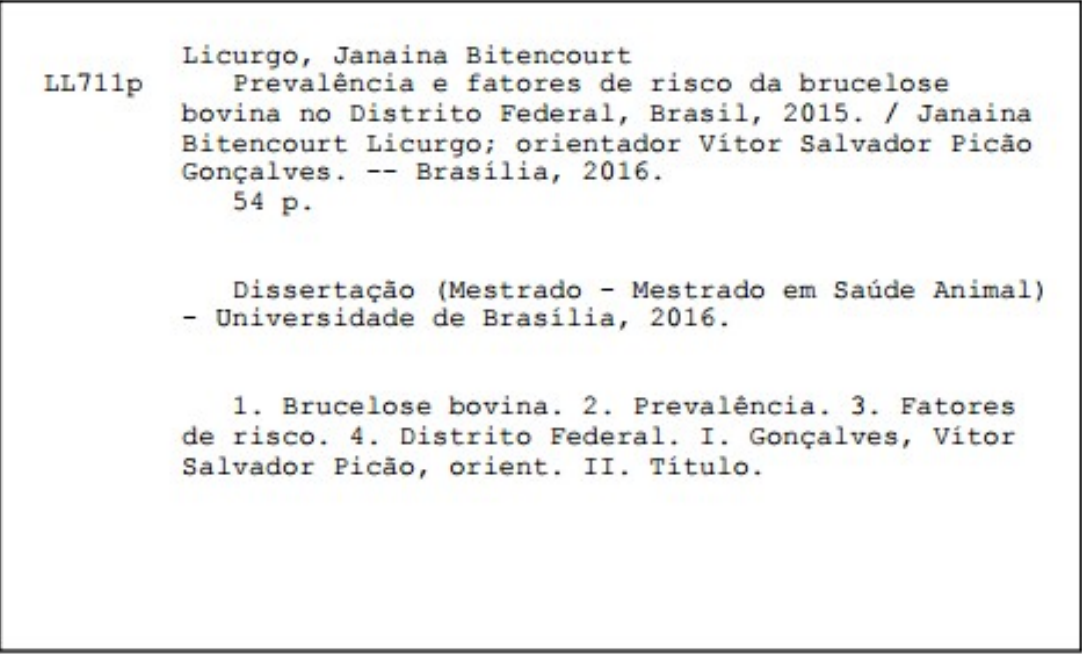


Ao melhor presente que eu poderia receber, Ana Bitencourt Machado. 


\section{AGRADECIMENTOS}

A Deus, pela força para completar essa jornada.

Ao meu marido André, por todo o companheirismo, atenção e por saber me acalmar nos momentos mais estressantes.

À minha filha Ana, por entender quando a mamãe tinha que trabalhar e dar o melhor sorriso nas piores horas.

Aos meus pais Marcos Antônio de Sousa Licurgo e Ester Bitencourt Licurgo, por sempre acreditarem em mim e por todo amor, apoio e confiança durante toda a minha trajetória pessoal e profissional.

À minha tia Ruth e prima Paulinha, pela presença constante na minha vida.

Ao meu orientador, Vítor Gonçalves, professor que há muito admiro, pelos ensinamentos, paciência e pelo voto de confiança ao aceitar me orientar no mestrado.

Aos professores da banca examinadora, Fernando Ferreira e Marcos Bryan, além do meu orientador, pela disponibilidade, oportunidade de discussão e todas as sugestões valiosas que enriqueceram essa dissertação.

À Ana Lourdes, parte fundamental nesse projeto, por aguentar meus desesperos, pelas orientações e toda a paciência.

Aos colegas de laboratório, pelo apoio e aconselhamentos.

Um agradecimento mais que especial a todos os colegas da Seagri, executores desse projeto. Sem eles, nada disso teria sido possível. Aos gestores, pela oportunidade e flexibilização de horários de trabalho.

Ao colegas de escritório, pelo apoio e compreensão nos momentos em que eu "entrava em alfa", só pensando nesse projeto. 


\section{RESUMO}

A brucelose é uma zoonose de distribuição mundial e acarreta importantes problemas sanitários e grandes prejuízos econômicos. Como parte de um acordo cooperativo entre diversos órgãos, a Secretaria de Agricultura, Abastecimento e Desenvolvimento Rural do Distrito Federal (Seagri) realizou, em 2015, um estudo transversal por amostragem com o objetivo de estimar a prevalência e analisar fatores de risco para brucelose bovina em seu território. O estudo teve o objetivo de subsidiar as estratégias do programa distrital para controle da enfermidade e promover ajustes nas atividades já realizadas, comparando os resultados encontrados com um estudo de prevalência realizado em 2003. As propriedades com criação de bovinos no Distrito Federal foram dividas em duas subpopulações, de acordo com o tamanho do rebanho. A primeira subpopulação foi formada por propriedades com até 15 (quinze) fêmeas com mais de 24 (vinte e quatro) meses, isto é, em idade reprodutiva. A segunda subpopulação, de rebanhos maiores, foi constituída por propriedades com 15 (quinze) ou mais fêmeas em idade reprodutiva. Para cada subpopulação foi amostrado aleatoriamente um número pré-estabelecido de propriedades. Em cada uma dessas propriedades, foi amostrado, também aleatoriamente, um número pré-estabelecido de fêmeas com mais de 24 (vinte e quatro) meses e aplicado um questionário com o objetivo de identificar fatores de risco associados com a presença da doença. Os animais selecionados foram submetidos ao teste do Antígeno Acidificado Tamponado - ATT, como teste de triagem e ao 2-Mercaptoetanol, como confirmatório. No total, foram amostradas 344 propriedades e 2.247 animais. A prevalência estimada de focos de brucelose para o Distrito Federal foi de 3,1\% [IC 95\%: 1,31\%; 4,9\%] e de animais foi de 0,93\% [IC 95\%: 0,16\%; $1,71 \%$ ]. As prevalências médias de focos e de animais não apresentaram diferenças estatisticamente significativas entre as duas subpopulações, apesar da identificação de tendência de prevalências maiores em rebanhos maiores. $\mathrm{O}$ único fator de risco associado à condição de foco foi a aquisição de animais com finalidade de reprodução, apresentando um valor de OddsRatio de 14,3 [IC 95\%: 3,04; 67,2]. Os resultados deste estudo indicam que a estratégia de vacinação não está contribuindo para diminuir a prevalência de brucelose bovina no Distrito Federal, tornando-se necessário intensificar o diagnóstico e eliminação dos animais positivos, adotando medidas de vigilância baseada em risco.

Palavras-chave: brucelose bovina, prevalência, fatores de risco, Distrito Federal. 


\begin{abstract}
Brucellosis is an important zoonosis with a worldwide distribution and causes important health problems and great economic losses. As part of a cooperative agreement among several agencies, the State Department of Agriculture, Supply and Rural Development of Distrito Federal, Brazil, carried out, in 2015, a cross-sectional study aimed at estimating the prevalence and analyzing risk factors for bovine brucellosis in its territory. The objective of the study was to support strategic decision-making of the district program, in order to control the disease and to promote adjustments in the activities already carried out, by comparing the results found in this study and the results of a prevalence study carried out in 2003. The properties in the territory of Distrito Federal were divided into two subpopulations, based on the size of the herd. The first subpopulation comprised properties with up to 15 females aged 24 months or greater. The second subpopulation of larger herds consisted of properties with 15 or more females aged 24 months or greater. For each subpopulation, a pre-determined number of properties were selected. In each property, a pre-determined number of females with 24 months of age or more were randomly selected and a questionnaire was used in order to identify the risk factors associated with the disease. Sera from the selected animals were initially screened with a buffered acidified plate antigen and confirmation by the 2Mercaptoethanol test. A total of 344 farms and 2,247 animals were selected. The prevalence of infected herds in Distrito Federal was 3.1\% [95\% CI: 1.31\%; 4.9\%] whereas the prevalence of infected animals was $0.93 \%$ [95\% CI: $0.16 \% ; 1.71 \%]$. There was no statistically significant difference between the prevalence of infected herds and animals in the two subpopulations, despite the identification of a trend of higher prevalence in larger herds. The only risk factor associated with the disease was the purchase of breeding animals. The value of Odds Ratio was 14.3 [95\% CI: $3.04 ; 67.2]$. These results suggest that the current vaccination scheme is not effective in lowering the prevalence of brucellosis in the Distrito Federal, which makes a case for intensifying risk-based surveillance strategies, with the test-and-slaughter procedures.
\end{abstract}

Keywords: bovine brucellosis, prevalence, risk factors, Distrito Federal. 


\section{LISTA DE FIGURAS}

Figura 1. Gráfico de notificações de brucelose humana no Brasil, por UF (2010 a

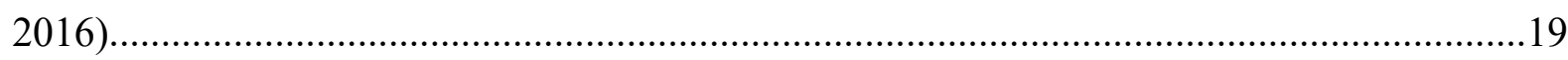

Figura 2. Boxplot do $\mathrm{n}^{\circ}$ de fêmeas com idade acima de 24 meses por propriedade amostrada

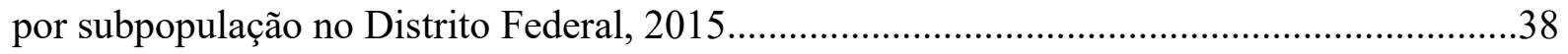

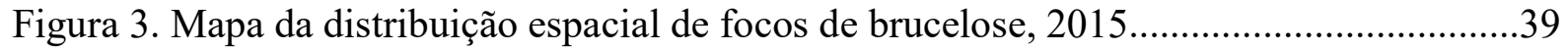

Figura 4. Mapa do trânsito de bovinos destinados ao Distrito Federal, 2015..........................43 


\section{LISTA DE TABELAS}

Tabela1. Dados censitários da população bovina do Distrito Federal, por tamanho de rebanho. .38

Tabela 2. Prevalência aparente de rebanhos para brucelose bovina no Distrito Federal, por tamanho de rebanho. 40

Tabela 3. Prevalência de brucelose bovina em vacas com 24 meses ou mais no Distrito Federal, por tamanho de rebanho.

Tabela 4. Prevalências e número provável de propriedades infectadas no Distrito Federal, por tamanho de rebanho.

Tabela 5. Número de produtores que adquiriram animais em dois anos, por tamanho de rebanho

Tabela 6. Número de produtores que adquiriram animais em dois anos, por tipo de criação e tamanho de rebanho.

Tabela 7. Número de produtores que declararam vacinar as fêmeas contra brucelose utilizando a B19, por tamanho de rebanho. .44

Tabela 8. Frequência de fêmeas vacinadas contra a brucelose, por tamanho de rebanho. . .44

Tabela 9. Frequência de produtores que declararam realizar testes diagnósticos para a brucelose, por tamanho de rebanho.

Tabela 10. Destino dos restos de aborto das vacas, por tamanho de rebanho. . .45

Tabela 11. Análise univariada da associação de tipos e práticas de produção animal com a presença de brucelose no rebanho. . .46

Tabela 12. Modelo de regressão logística usando método design-based. .47 


\section{LISTA DE ABREVIATURAS E SIGLAS}

2-ME - teste do 2-Mercaptoetanol

AAT - teste do antígeno acidificado tamponado

CID-10 -Classificação Internacional de Doenças

DF - Distrito Federal

FC - teste de fixação de complemento

Mapa - Ministério da Agricultura, Pecuária e Abastecimento

PNCEBT - Programa Nacional de Controle e Erradicação da Brucelose e da Tuberculose Bovina

Seagri - Secretaria de Estado da Agricultura, Abastecimento e Desenvolvimento Rural 


\section{SUMÁRIO}

\section{CAPÍTULO I}

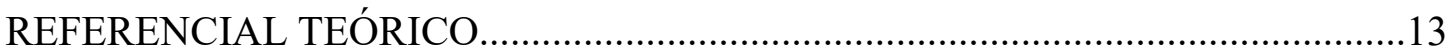

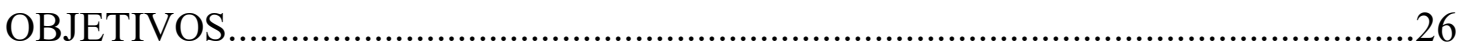

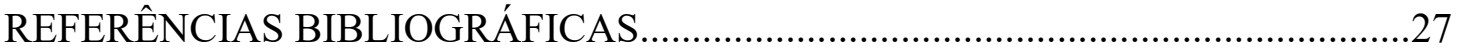

CAPÍTULO II

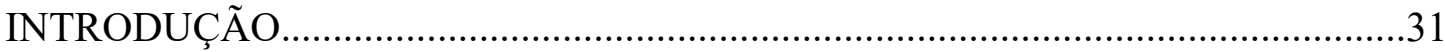

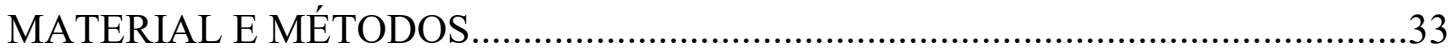

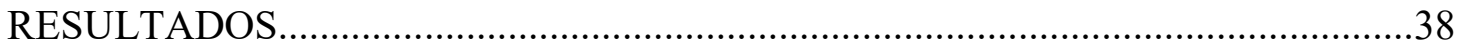

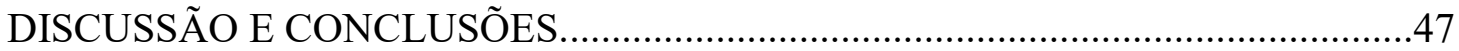

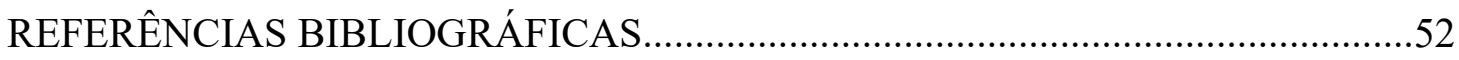




\section{CAPÍTULO I}

\section{REFERENCIAL TEÓRICO}

\section{Brucelose}

A brucelose é uma doença infectocontagiosa que acomete animais domésticos e selvagens, com impactos significativos para a saúde pública, saúde animal e comércio internacional. A doença é causada por bactérias do gênero Brucella (USDA-APHIS, 2012). A maior incidência da doença é observada no Oriente Médio, na região do Mediterrâneo, África Subsariana, China, Índia, Peru e México. Os países da Ásia Central e Sudeste Asiático atualmente apresentam os maiores aumentos na incidência (OIE, 2016).

A brucelose bovina é uma doença causada quase exclusivamente pela bactéria Brucella abortus. A infecção causa principalmente abortos em bovinos e bubalinos e provoca doença normalmente crônica no homem (ZINSSTAG et al., 2015).

Os abortos costumam ocorrer após a primeira infecção. Após essa primeira fase, o animal desenvolve imunidade celular e os abortos se tornam menos frequentes e até raros nas gestações subsequentes. A partir de então, os sinais clínicos mais observados são diminuição da fertilidade, nascimento de animais fracos ou natimortos e redução na produção de leite, entre outros (OIE, 2016).

O trato digestivo é a principal porta de entrada do agente. $\mathrm{O}$ animal prenhe elimina grande quantidade da bactéria quando aborta e durante todo o período puerperal (ZINSSTAG et al., 2015). O agente patogênico eliminado pode então contaminar pastagens, água, alimentos e fômites, podendo causar infecção em outro animal susceptível quando este ingere um desses meios contaminados. A bactéria pode sobreviver em ambiente externo por vários meses, especialmente em climas frios e úmidos. O hábito de lamber as crias recém-paridas também é importante fonte de infecção. Apesar de mais raros, há relatos de infecção pela entrada da bactéria através das mucosas do nariz e dos olhos (BRASIL, 2006).

\section{Agente patogênico}

As bactérias do gênero Brucella são cocobacilos Gram-negativos, parasitas intracelulares facultativos, imóveis, com predileção por hospedeiro específico (ZINSSTAG et al., 2015). 
O gênero Brucella expandiu recentemente para mais de 10 espécies, todas associadas a mamíferos, cada uma com hospedeiro preferencial. Apesar de predileção por hospedeiro, a maioria das espécies de Brucella é capaz de infectar outras espécies animais (OIE, 2016).Dessas espécies, seis são denominadas “clássicas": B. abortus (bovinos e bubalinos), $B$. melitensis (ovinos e caprinos), B. suis (suínos), B. ovis (ovinos), B. canis (cães) e B. neotomae (rato do deserto). Durante as últimas décadas outras espécies foram isoladas: B. microti (roedores), B. inopinata (isolado de infecção em prótese mamária de humanos), B. papionis (isolado de babuíno natimorto), B. vulpis (raposas), e B. ceti e B. pinnipedialis, ambas isoladas de mamíferos marinhos (SOLER-LLORÉNS et al., 2016).

No Brasil, são poucos os estudos visando a identificação das variedades de Brucella. Já foram identificados biovares de B. abortus, B suis, B. canis e B. ovis infectando animais domésticos, porém não houve até hoje detecção de $B$. melitensis, principal agente etiológico da brucelose em caprinos e ovinos (BRASIL, 2006).

Vários relatos na literatura científica indicam infecção de espécie de Brucella em animais que não são seus hospedeiros preferenciais (OCHOLI et al., 2005; MORALESESTRADA et al., 2016), mas estes tipos de infecções não são comuns. Lucero et al. (2008), em análise realizada em isolados da bactéria obtidos de animais e humanos da América Latina, confirmou a preferência das espécies de Brucella por hospedeiro específico. Das diversas amostras identificadas em seu estudo, 97,5\% dos isolados de bovinos eram $B$. abortus; 98,6\% de caprinos eram B. melitensis; 96,4\% de suínos eram B. suis e 98,6\% dos isolados de ovinos eram B. ovis.

As infecções cruzadas observadas normalmente podem ser creditadas a práticas de manejo inadequadas em propriedades que tenham criações mistas, com diferentes espécies animais convivendo no mesmo espaço. Além disso, ainda que várias espécies domésticas ou silvestres sejam susceptíveis à infecção por B. abortus, a maioria atua como hospedeiro final da infecção, não transmitindo a doença para outros animais (BRASIL, 2006). Somente a situação em suínos é diferente, já que estes podem atuar como hospedeiro mantenedor para $B$. abortus (GODFROID et al., 2013).

Infecções de animais de vida livre por diferentes espécies de Brucella também são amplamente divulgados na literatura. Dados de notificação da OIE indicam muitos casos suspeitos ou confirmados de brucelose em animais silvestres, especialmente infecção por $B$. 
suis e B. melitensis. Embora com menor frequência, há notificações de infecção por $B$. abortus em animais de vida livre em vários países do mundo. O papel desses animais como possíveis fontes de infecção não é conhecido (ZINSSTAG et al., 2015), e a falta de conhecimento pode ser um importante complicador para os esforços de erradicação da doença, levando em consideração a proximidade dos animais de vida livre com os rebanhos domésticos em vários países. O papel dos bisões selvagens, especialmente nos Estados Unidos, cervídeos em diversos países da Europa e suídeos selvagens em vários países, como fontes de disseminação da brucelose vem sendo amplamente discutido (GODFROID et al., 2013).

\section{Perdas econômicas}

A brucelose bovina causa importantes perdas econômicas, diretas e indiretas. As perdas diretas são decorrentes, principalmente, de abortos, baixos índices reprodutivos, aumento do intervalo entre partos, diminuição da produção de leite, morte de bezerros e interrupção de linhagens genéticas, além de depreciação do valor comercial dos animais de propriedades positivas. Estimativas mostram diminuição de $25 \%$ na produção de leite e de carne e de $15 \%$ na produção de bezerros em decorrência da infecção pela brucelose bovina. Dentro das perdas indiretas, destaque especial deve ser dado aos gastos decorrentes da infecção humana. Além dos gastos com internação e tratamento de pessoas acometidas pela doença, destaca-se também o custo do período decorrente da ausência ao trabalho (BRASIL, 2006).

Nos Estados Unidos, estimou-se, em 1983, que as perdas por brucelose bovina foram da ordem de 32 milhões de dólares (BRASIL, 2006). Na Argentina, as perdas anuais foram estimadas em 60 milhões de dólares (SAMARTINO, 2002). No Brasil, são poucos os estudos sobre os prejuízos econômicos ocasionados pela brucelose bovina ou bubalina. Santos et al. (2013) estimou que as perdas devidas à brucelose bovina no Brasil foram da ordem R\$420,12 ou R \$226,47 para cada fêmea infectada acima de 24 meses em rebanhos de leite ou corte, respectivamente. O prejuízo total, baseado nos resultados dos inquéritos realizados entre 2001 e 2003, foi de, aproximadamente, 892 milhões de reais. Os mesmos autores ainda estimaram que a cada $1 \%$ de variação na prevalência o custo da brucelose bovina no Brasil pode variar em 155 milhões de reais.

Em outro estudo realizado no município de Pirassununga, em São Paulo, foram calculadas perdas anuais para o município de valores acima de 132 mil reais para a brucelose 
bovina.Os valores descritos são referentes à época de realização do estudo, no ano de 2003, sem atualizações. Os cálculos foram baseados em um rebanho de 16.700 bovinos distribuídos em 750 propriedades, com prevalência da doença em animais de até 2,2\% e de focos de 11 a 28,4\% (HOMEM et al., 2016b).

Os estudos normalmente são feitos levando em consideração as estimativas de gastos que o produtor teria principalmente com as perdas diretas da doença, como abortos, infertilidade das vacas, redução na produção de leite e carne, reposição de animais de reprodução no rebanho, entre outras. As estimativas das perdas econômicas divulgadas em diversos estudos indicam que a brucelose bovina tem um impacto significativo para a produção pecuária do país.

\section{Saúde Pública}

A brucelose é uma zoonose altamente infecciosa para o homem, causando uma doença conhecida como Febre Ondulante ou Febre de Malta, desde a sua descoberta em Malta durante os anos de 1850 (OIE, 2016). É uma doença de difícil diagnóstico porque apresenta sinais clínicos inespecíficos. Os sintomas mais comuns são febre, sudorese noturna com odor peculiar, fraqueza, calafrios e dores musculares (SELEEM et al., 2010). A manifestação da doença normalmente provoca o afastamento parcial ou total do trabalho.

Os sintomas da doença no homem são muito variáveis. Geralmente, B. melitensis causa sinais clínicos mais severos, com infecção aguda. As formas menos severas da doença, normalmente de evolução crônica, são causadas principalmente por B. suis e B. abortus (ZINSSTAG et al., 2015).

A enfermidade tanto pode manifestar-se de forma branda, com evolução para a cura espontânea, quanto grave e prolongada, acompanhada por toxemia. Outras complicações relatadas são trombocitopenia, endocardite e outras, podendo levar à morte (BRASIL, 2006). Sintomas neurológicos relacionados à doença são raros, mas também relatados. Um estudo na Turquia acompanhou a evolução de 18 casos de neurobrucelose em humanos, todas com complicações neurológicas irreversíveis. Os autores alertam ainda para o risco de a doença não ter o diagnóstico correto, já que vários sinais da neurobrucelose podem ser confundidos com outras doenças neurológicas (CERAN et al., 2011).

Humanos são infectados por contato direto com animais infectados ou pelo consumo de leite cru ou de produtos lácteos não submetidos a tratamento térmico, oriundos de animais 
infectados (ZINSSTAG et al., 2015). A carne crua e o sangue de animais infectados podem conter microorganismos viáveis e, portanto, representam risco para o homem (BRASIL, 2006). A melhor forma de prevenção para a brucelose humana é o controle e eliminação de animais positivos (OIE, 2016). Em estudo realizado na região central da Grécia, foi observado que o contato direto com animais contaminados ou seus produtos foi a fonte de infecção principal para os casos de brucelose humana naquela região. $\mathrm{O}$ consumo de produtos contaminados foi responsável pela infecção em apenas 8,49\% dos casos (MINAS et al., 2007).

A distribuição geográfica da brucelose humana está constantemente mudando, com novas regiões endêmicas surgindo ou ressurgindo. A epidemiologia da brucelose humana mudou drasticamente durante as últimas décadas por razões sanitárias, socioeconômicas e políticas, além do aumento de viagens internacionais (SELEEM et al., 2010).Diversas áreas tradicionalmente consideradas endêmicas (França, Israel, vários países da América Latina) conseguiram controlar a doença. Por outro lado, novas áreas endêmicas foram identificadas, particularmente na Ásia Central, enquanto a situação de certos países do Oriente Médio vem piorando drasticamente. A Síria atualmente é o país com mais notificações anuais de brucelose humana. Vários dos países com as maiores incidências anuais estão situados no continente asiático (Irã, Iraque, Síria, Mongólia). Além disso, nessa região estão diversas Repúblicas da extinta União Soviética, onde a re-emergência da brucelose humana é um grande problema (PAPAS et al., 2006).

A maioria dos países do norte da Europa (Alemanha, Inglaterra, Holanda, Dinamarca, Suécia) é considerada livre de brucelose humana e o risco de uma re-emergência não é considerado, pois esses países possuem um sistema de vigilância eficiente. A brucelose humana continua endêmica em algumas regiões da Espanha, Portugal, Itália, e países como Grécia, Turquia, Albânia, Macedônia (SELEEM et al., 2010). Nessas regiões, a doença é causada principalmente por $B$. melitensis e muito associada ao consumo de derivados do leite de pequenos ruminantes sem tratamento térmico adequado.

Nos Estados Unidos, a brucelose humana também é causada principalmente por $B$. melitensis, afetando principalmente a população hispânica, e localizada em áreas próximas à fronteira com o México. A doença é migrada através da fronteira principalmente através de produtos lácteos contaminados (PAPAS et al., 2006).O México é tradicionalmente um dos países endêmicos para a brucelose humana. A América do Sul também é tradicionalmente 
considerada endêmica para a brucelose humana, especialmente o Peru e a Argentina. A $B$. melitensis é prevalente no Peru e no oeste da Argentina, e B. abortus no leste da Argentina e outros países. Não há dados disponíveis na OIE sobre brucelose humana no Brasil, e a subnotificação pode ser um obstáculo para a avaliação da real incidência da brucelose humana no Brasil e países vizinhos (PAPAS et al., 2006).Aproximadamente 500 mil casos de brucelose humana são reportados anualmente no mundo, mas estima-se que o número de casos não notificados devido aos sintomas inespecíficos da doença seria dez vezes maior (GODFROID et al., 2013).

Em uma análise retrospectiva feita com isolados de Brucella de humanos e animais na América Latina (especialmente Argentina, México e Peru) no período de 1968 a 2006, B. melitensis e B. suis foram os principais agentes patogênicos identificados na brucelose humana. Brucella melitensis foi responsável pela brucelose humana em mais de $70 \%$ dos casos. A infecção por B. abortus apresentou uma queda ao longo do período estudado. B. suis foi isolada na maior parte dos casos de brucelose em suínos, mas também em um número considerável de bovinos e cães. O papel desses animais como fonte de infecção de B. suis para humanos ainda não foi estudado (LUCERO et al., 2008).

Poucos estudos sobre a brucelose humana no Brasil são conduzidos. Os poucos publicados indicam que a doença é mais frequente nas áreas rurais, mais comum em homens que em mulheres (pela natureza da ocupação) e pessoas entre 20 e 49 anos (POESTER et al., 2002).

Os dados de brucelose humana no Brasil são obtidos a partir de dados de morbidade e internações em hospitais. A lista de internações, com o CID-10 referente à brucelose, indica 147 casos no período de janeiro de 2010 a agosto de 2016, com uma média anual em torno de 21 casos (DATASUS, 2016). São Paulo é o estado com mais internações decorrentes do diagnóstico de brucelose, talvez pelo fato de, além de ser o mais populoso do país, é onde a população das áreas rurais tem mais acesso à assistência médica, quando comparado ao resto do país. As poucas notificações observadas nos estados da região Centro-Oeste, que apresentam as maiores prevalências para a brucelose bovina do país, sugerem que a subnotificação seja um fator preocupante, especialmente nessas áreas. 
Figura 1. Gráfico de notificações de brucelose humana no Brasil, por UF (2010 a 2016).

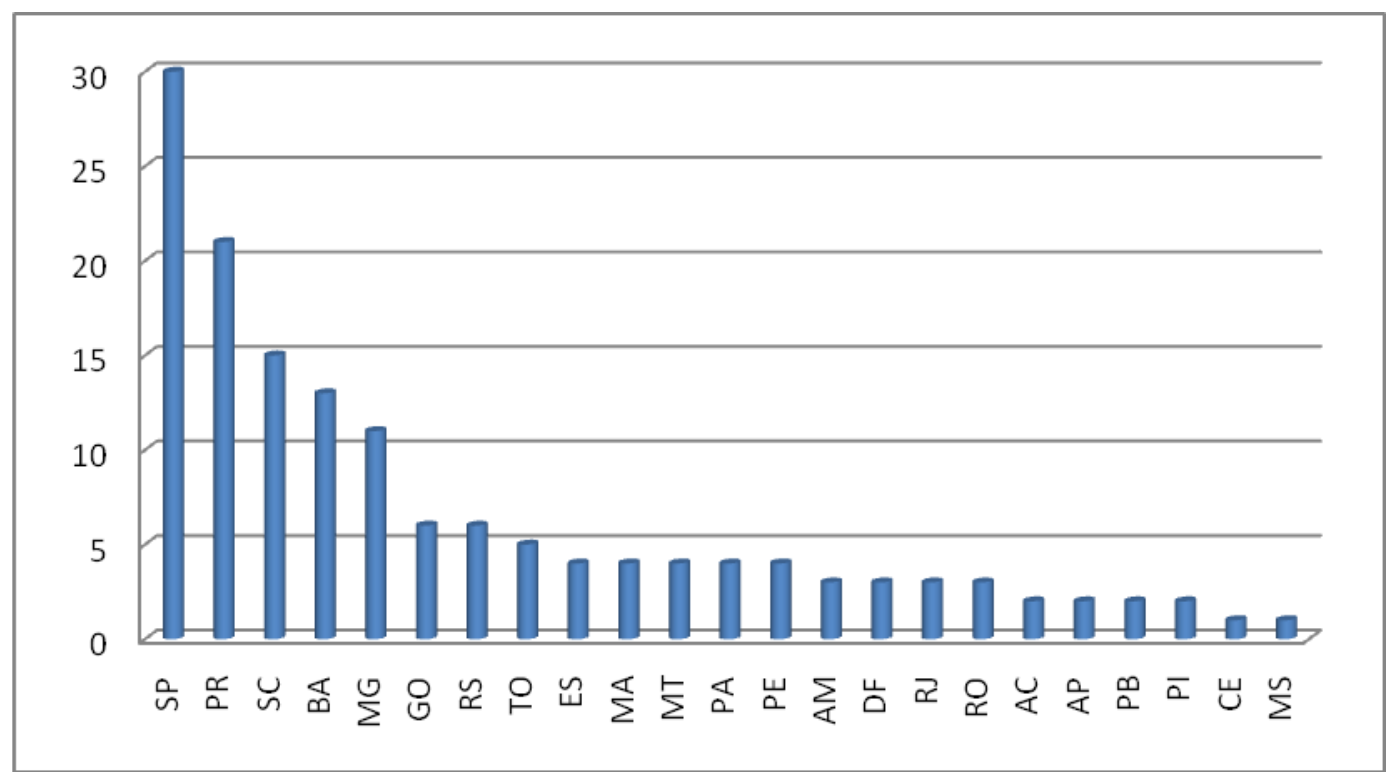

Fonte: Elaborado pelo autor, a partir de DATASUS (2016)

Homem et al (2016a) conduziram estudo sorológico de prevalência da brucelose em bovinos e humanos em propriedades caracterizadas como familiares no município de Uruará, Pará. Foram detectadas prevalências de focos de brucelose bovina de 52\% [42\% - 63\%] e de núcleos familiares com pelo menos um indivíduo positivo de $21 \%$ [13\% - 31\%]. A alta prevalência de infecção em bovinos foi considerada a causa principal para a alta exposição observada em humanos. Diversos estudos realizados em outros países também comprovaram que quando a incidência de brucelose é controlada nos reservatórios animais, existe um declínio significativo na incidência da doença no homem (SELEEM et al., 2010).

A brucelose é uma zoonose que apresenta um forte componente de caráter ocupacional. Tratadores de animais, veterinários, magarefes, trabalhadores de indústrias de laticínios e de frigoríficos formam importante grupo de risco para a doença. Em um matadouro municipal de São Luís, no Maranhão, verificou-se uma taxa de soropositividade aos testes de diagnóstico para brucelose de 5,97\% em bovinos, e de 10,17\% em trabalhadores do estabelecimento (SANTOS et al., 2007).Na região de Araguaína, no norte de Tocantins, em pesquisa conduzida com grupos de risco para a brucelose, como trabalhadores de frigorífico, veterinários e trabalhadores de fazendas, foi encontrada uma soropositividade de $4 \%$ aos testes de brucelose. Dos positivos, mais de $88 \%$ eram homens e trabalhadores de frigoríficos (RAMOS et al., 2008).Um estudo no município de Correntes, em Pernambuco, tentou estabelecer uma ligação entre a brucelose bovina e o risco de infecção nas populações expostas. Das amostras coletadas em bovinos e trabalhadores, $6,8 \%$ dos bovinos e $1,8 \%$ dos 
humanos reagiram positivamente ao teste de AAT. Porém, como nenhuma amostra reagiu ao teste de 2-ME e FC, fatores de risco não puderam ser analisados (TENÓRIO et al., 2008).

Como uma das zoonoses mais disseminadas no mundo, a brucelose é um importante exemplo da importância do enfoque no conceito de "One Health" para prevenção e controle da doença (ZINSSTAG et al., 2015). Os trabalhos sobre brucelose normalmente focam na presença ou ausência da doença em determinada espécie animal ou no homem. Como já destacado, os estudos mais atualizados mostram que uma mesma espécie de Brucella pode infectar mais de uma espécie animal, e o papel de várias dessas espécies na epidemiologia da doença não são bem conhecidos. Assim, os estudos deveriam abranger especialistas de diversas áreas (medicina, veterinária, ecologia e sociologia) para contribuir com uma compreensão holística da doença (GODFROID et al., 2013).

\section{Situação epidemiológica da brucelose bovina no Brasil}

A brucelose bovina causada por Brucella abortus é a infecção brucélica mais prevalente no Brasil, seguida por B. suis em suínos. Alguns estudos já isolaram B. abortus e B. suis em bovinos, além de isolar B. abortus em equinos e cães. A B. melitensis e $B$. neotomae nunca foram isoladas no país. A epididimite ovina, causada por $B$. ovis, também é endêmica no Brasil (POESTER et al., 2002).

Diversos estudos mostram que a brucelose bovina está disseminada por todo o território brasileiro, com maior ou menor prevalência dependendo da região estudada. Em 1975, foram verificadas as seguintes prevalências em animais, por regiões: Sul, 4\%; Sudeste, 7,5\%; Centro-Oeste, 6,8\%; Nordeste, 2,5\% e Norte, 4,1\%. Posteriormente, alguns estados isolados investiram em estudos sorológicos próprios, mas estes não mostraram grandes alterações em relação aos índices regionais verificados (BRASIL, 2006).

Em 2001, o Ministério da Agricultura, Pecuária e Abastecimento implantou o Programa Nacional de Controle e Erradicação da Brucelose e da Tuberculose Animal PNCEBT, que incluiu a realização de inquéritos sorológicos, visando estimar a prevalência e análise de fatores de risco associados à presença das doenças nos rebanhos, como ferramentas para a tomada de decisões do Programa. Nesse primeiro momento, diversos estados brasileiros realizaram estudos sorológicos, e os resultados mostraram uma situação de endemia em todas as regiões do Brasil. A análise de fatores de risco baseada nos estudos transversais realizados em 14 (quatorze) Unidades da Federação revelou que, em geral, modos 
de produção extensivos, a aquisição de reprodutores e o tamanho do rebanho são fatores de risco para a doença nos estados em que os estudos haviam sido realizados (MOTA et al., 2016).

Hoje a situação epidemiológica da brucelose já é conhecida em detalhes em 18 (dezoito) estados do Brasil, que possuem aproximadamente $85 \%$ do rebanho bovino nacional. Oito desses estados já conduziram um segundo estudo para verificar a eficácia das medidas implementadas, para promover melhorias nos processos de controle e/ou erradicação da doença (FERREIRA NETO et al., 2016).

O segundo estudo revelou uma queda significativa nos índices de prevalência para a brucelose bovina em Rondônia, Mato Grosso e Mato Grosso do Sul. Estes estados apresentaram índices elevados de prevalência de focos (acima de 35\%) no primeiro estudo, e investiram em programas de vacinação compulsória para baixar a prevalência em um primeiro momento (LEAL FILHO et al., 2016; BARDDAL et al., 2016; INLAMEA et al., 2016). Os resultados do segundo estudo demonstraram que, em regiões com altas prevalências de brucelose bovina, a implementação de uma estratégia de vacinação para o controle da doença é eficaz. Estados como Espírito Santo, Rio Grande do Sul e São Paulo, que já tinham apresentado índices baixos de prevalência no estudo realizado há quase uma década, não apresentaram diferenças significativas nesses índices (FERREIRA NETO et al., 2016).

Minas Gerais pode ser considerado um bom exemplo de sucesso no país, já que, mesmo com prevalências consideradas baixas para os padrões nacionais, ainda conseguiu uma redução significativa nesses índices, através de um programa de vacinação compulsória com a vacina B19 lançado em 1993, anos antes da implementação do PNCEBT. No estudo realizado em 2002, a prevalência no estado de focos de brucelose bovina era de 6,04\% [IC 95\%: 4,98 7,10\%]. Esse índice baixou para 3,59\% [IC 95\%: 2,76 - 4,42\%] no segundo estudo, realizado em 2011. Porém, foi demonstrado que, em regiões com baixas prevalências, programas de vacinação compulsória não são eficazes, já que nos dois estudos o estado foi dividido nos mesmos sete estratos regionais, e os únicos estratos que apresentaram significativa redução na prevalência foram as regiões do Leste e Triângulo Mineiro, que apresentaram altas prevalências no estudo anterior (OLIVEIRA et al., 2016).

Em modelagem feita sobre os benefícios de campanhas de vacinação em dois estados brasileiros com diferentes prevalências e realidades, também foi evidenciado que regiões com altas prevalências de brucelose bovina teriam maiores vantagens econômicas na adoção de 
uma estratégia de vacinação para o controle da doença. O estudo demonstrou ainda que índices de vacinação em torno de $90 \%$ de cobertura apresentam um melhor razão benefíciocusto quando comparado a índices de vacinação em torno de 70\% e 80\% (ALVES et al., 2015).

Os últimos estudos demonstraram que a brucelose bovina continua disseminada no território, apresentando grande heterogeneidade. As prevalências maiores continuam em regiões com maior concentração de bovinocultura de corte e rebanhos grandes continuam sendo fatores de risco em várias regiões (OLIVEIRA et al., 2016; BAUMGARTEM et al. 2016; LEAL FILHO et al. 2016).

Santa Catarina é o único estado do Brasil com prevalências de focos e de animais muito baixas em todas as regiões, e está em fase de erradicação da doença, com proibição da vacinação de bezerras utilizando a B19 desde 2004. O estado está em fase de intensificação de estratégias para detecção e eliminação de animais positivos, e as medidas incluem a notificação de animais reagentes aos testes realizados para o trânsito animal, testes para a detecção de anticorpos no leite e em derivados lácteos. O sistema de vigilância estadual também está começando a delinear estudo de caso-controle usando os focos detectados ao longo do tempo (BAUMGARTEM et al. 2016).

\section{Programas de controle e erradicação}

Classicamente, após uma primeira fase em que a brucelose é controlada por vacinação compulsória, esta é gradualmente reduzida e eventualmente proibida, quando as medidas de testes e eliminação de animais positivos são intensificadas para erradicar a doença. Normalmente necessita-se de mais de uma década para erradicar uma doença utilizando a política de eliminação de animais positivos. Chave para o sucesso da medida de eliminação é uma compensação financeira para os produtores que tiverem seus animais sacrificados (GODFROID et al., 2013).

Em países desenvolvidos, por mais de quatro décadas, programas de controle e erradicação da brucelose em animais foram implantados pelos serviços veterinários oficiais. Ainda assim, apenas alguns países conseguiram eliminar a circulação de B. abortus em seus rebanhos de animais domésticos, demonstrando a dificuldade de controlar de forma eficiente uma doença disseminada mundialmente e com capacidade de infectar diversas espécies animais. Com exceção de alguns países europeus e o Canadá, os demais países que 
conseguiram erradicar B. abortus em seus rebanhos domésticos são ilhas (ALVES et al., 2015).

No Brasil, o Ministério da Agricultura, Pecuária e Abastecimento normatiza o controle da brucelose desde 1944. Um decreto desse ano exigia a identificação de todos os animais vacinados (POESTER et al., 2002). Vários outros decretos foram emitidos sobre o mesmo tema, assim como regulamentos para importação e exportação de animais e regulamentação de testes diagnósticos. Em 1976, outro decreto propunha um programa nacional, baseado em vacinação de fêmeas, diagnóstico de rebanho e eliminação de animais positivos. As atividades de vacinação e eliminação de animais positivos seriam de adesão voluntária (BRASIL, 2006). Esse programa nunca foi devidamente implementado, e enquanto isso alguns estados, como o Rio Grande do Sul e Minas Gerais, implementavam suas próprias medidas de controle, voltadas principalmente para a vacinação de fêmeas (POESTER et al., 2002).

Em 2001, foi instituído o PNCEBT, regulamentando medidas compulsórias e voluntárias. Ainda vigentes, as medidas compulsórias incluem a vacinação de fêmeas entre três e oito meses com a B19, exigência de testes diagnósticos para a movimentação interestadual de reprodutores ou para participação de exposições e feiras e a eliminação de animais positivos aos testes diagnósticos. A certificação de propriedades livres para a brucelose ou a tuberculose, é a única medida voluntária prevista pelo programa e tem como objetivo envolver os diversos atores do setor produtivo, industrial e a comunidade no conrole e erradicação da doença (BRASIL, 2006).

Embora os programas de vacinação contra brucelose estejam bem implantados na maioria dos estados do Brasil, os índices de vacinação normalmente estão abaixo de $100 \%$, e poucos produtores certificaram suas propriedades como livres de brucelose, dificultando o planejamento das atividades de fiscalização (ALVES et al., 2015). Analisando a evolução do PNCEBT desde a sua implementação, Ferreira Neto et al. (2016) constataram que a evolução do programa tem sido limitada pela dificuldade em engajar as cadeias produtivas de carne e leite como verdadeiros parceiros no processo.

Os custos para a certificação de uma propriedade como livre de brucelose são altos, e a demora em obter retorno de seus investimentos faz com que o produtor não veja benefícios para aderir à certificação de sua propriedade. Lôbo (2008), em estudo feito para identificar fatores econômicos que influenciam a viabilidade financeira da certificação de propriedades produtoras de leite como livres para a tuberculose bovina, concluiu que a razão benefício- 
custo é muito sensível à média de produção leiteira no estabelecimento e ao recebimento de adicional no preço do leite, e pouco sensível à variação de custos dos serviços veterinários.

Outro estudo, utilizando modelos de análise custo-benefício para a certificação de dois tipos de rebanhos leiteiros como livres para brucelose e tuberculose, também concluiu que a escala de produção teve grande influência no resultado econômico da propriedade. Ficou demonstrado que o retorno do investimento é mais lento para os produtores menos eficientes e com menor produção. Nessas propriedades, os benefícios oriundos do processo de certificação (maior produtividade, saneamento do rebanho) não foram capazes de pagar o investimento inicial no horizonte de tempo estudado, de cinco anos. O estudo também constatou que a certificação da propriedade como livre de brucelose bovina teve um maior impacto econômico que a tuberculose bovina (Leite, 2012).

Outro limitador para o sucesso do programa é o curto período de tempo em que a vacina B19 pode ser aplicada nas bezerras. Ainda assim, desde 2004, vem sendo observado um aumento significativo no número de fêmeas vacinadas utilizando a B19, com grandes diferenças entre os estados. Além disso, hoje a vacina RB51 é uma prática alternativa para a B19 em áreas com dificuldade de manejo dos rebanhos, como na área do Pantanal (LEAL FILHO et al., 2016).

Assim, tendo em vista os resultados nos diversos estudos e a dinâmica da situação epidemiológica da brucelose bovina no Brasil, o PNCEBT foi revisto no ano de 2015 por um grupo de trabalho composto por profissionais do MAPA e outras instituições públicas do país, e várias modificações foram propostas e normatizadas. As principais são as que seguem:

- A vacina RB51 poderá ser utilizada em substituição à B19, em bezerras não vacinadas entre três e oito meses, ou em regiões onde as condições geográficas dificultem o manejo dos rebanhos bovinos;

- Metodologia para classificação dos estados, levando em consideração a prevalência do estado e avaliação do serviço veterinário oficial estadual. Estratégias de controle e erradicação da brucelose diferenciadas, de acordo com a classificação de risco para a doença (BRASIL, 2016);

- Obrigatoriedade de saneamento de todo foco da doença para os estados classificados como de risco baixo, muito baixo ou desprezível (com valores de prevalência de brucelose bovina menores que 5\%); 
- Redução de três para dois testes negativos de rebanho, para certificação de propriedades livres para a enfermidade.

Essas medidas visam melhorar a dinâmica do programa, aumentar os índices de vacinação naquelas regiões em que programas de vacinação ainda possam baixar a prevalência da brucelose bovina, incentivar os produtores a certificar seus rebanhos como livres da doença, intensificação da detecção rápida e eliminação de animais positivos, além de estimular uma competição saudável entre os serviços veterinários estaduais (FERREIRA NETO et al., 2016).

Por último, o programa passa a exigir que as autoridades locais de saúde humana sejam informadas oficialmente sobre focos de brucelose e de tuberculose (BRASIL, 2016), estimulando uma aproximação entre as autoridades de saúde animal e humana e demonstrando preocupação com o caráter zoonótico das enfermidades.

A metodologia de classificação dos estados, de acordo com o PNCEBT revisado, leva em consideração dois fatores: prevalência da brucelose bovina, estimada em estudos padronizados pelo MAPA e as ações para controle e erradicação da doença, descritas em um Plano de Ação (BRASIL, 2016). O Plano de Ação deve ser elaborado pelo órgão de Defesa Sanitária Animal estadual e aprovado em conjunto com o MAPA. Assim, conhecer a situação epidemiológica atualizada da brucelose bovina no Distrito Federal, fornecendo subsídios para auxiliar na decisão de quais estratégias seriam mais eficientes para a realidade local, torna-se de fundamental importância. 


\section{OBJETIVOS}

\section{OBJETIVO GERAL:}

Caracterizar a situação epidemiológica da brucelose bovina no Distrito Federal.

\section{OBJETIVOS ESPECÍFICOS:}

- Estimar a prevalência de focos de brucelose bovina no Distrito Federal;

- Estimar a prevalência de brucelose bovina em fêmeas em idade reprodutiva no Distrito Federal;

- Identificar fatores de risco associados à presença da doença nos rebanhos bovinos do Distrito Federal;

- Fornecer subsídios para a adequação e melhoria do programa estadual de controle da doença no Distrito Federal. 


\section{REFERÊNCIAS BIBLIOGRÁFICAS}

ALVES, A.J.S., ROCHA, F., AMAKU, M.,et al. Economic analysis of vaccination to control bovine brucellosis in the States of São Paulo and Mato Grosso, Brazil. Preventive Veterinary Medicine, v.118, p.351-358, 2015.

BARDDAL, J.E.I, QUIXABEIRA-SANTOS, J.C., LOPES, I.F., et al. Effect of vaccination in lowering the prevalence og bovine brucellosis in the state of Mato Grossi, Brazil. Semina: Ciências Agrárias, v.37, n.5, Suplemento 2, p.3479-3492, 2016.

BAUMGARTEM, K.D., VELOSO, F.P., GRISI FILHO, J.H.H., et al. Prevalence and risk factors for bovine brucellosis in the State of Santa Catarina, Brazil. Semina: Ciências Agrárias, v.37, n.5, Suplemento 2, p.3425-3436, 2016.

BRASIL 2006. Programa Nacional de Controle e Erradicação da Brucelose e da Tuberculose Animal (PNCEBT): Manual Técnico. Ministério da Agricultura Pecuária e Abastecimento, Brasília, DF. 188p.

BRASIL 2016. IN n 19, de 10 de outubro - Estabelece o Regulamento Técnico do Programa Nacional de Controle e Erradicação da Brucelose e da Tuberculose Animal - PNCEBT e a Classificação das Unidades da Federação de acordo com o grau de risco para as doenças brucelose e tuberculose. Ministério da Agricultura Pecuária e Abastecimento. $<$ www.agricultura.gov.br> Acesso em 1nov 2016.

CERAN, N., TURKOGLU, R., ERDEM, I., et al. Neurobrucellosis: clinical, diagnostic, therapeutic features and outcome. Unusual clinical presentations in an endemic region. Braz. J. Infect. Dis., 15(1), p.52-59, 2011.

DATASUS 2016. Morbidade Hospitalar do SUS - por local de residência - Brasil. $<$ http://www2.datasus.gov.br/DATASUS/index.php?area=0203> Acesso em 06 nov 2016.

FERREIRA NETO, J.S., SILVEIRA, G.B., ROSA, B.M., et al. Analysis of 15 years of the National Program for the Control and Erradication of Animal Brucellosis and Tuberculosis, Brazil. Semina: Ciências Agrárias, v.37, n.5, Suplemento 2, p.3385-3402, 2016.

GODFROID, J., AL DAHOUK, S.,PAPPAS, G., et al. A “One Health" surveillance and control of brucellosis in developing countries: Moving away from improvisation. 
Comparative Immunology, Microbiology and Infectious Diseases, v.36, Issue 3, p.241-248, 2013.

HOMEM, V.S.F., HEINEMANN, M.B., HIGA, Z.M.M.Bovine and human brucellosis in the Trans-Amazonian agricultural frontier, Uruará, Pará, Brazil. Semina: Ciências Agrárias, v.37, n.5, Suplemento 2, p.3803-3808, 2016a.

HOMEM, V.S.F., HIGA, Z.M.M., FERREIRA NETO, J.S. Proposed model to study the economic impact of bovine brucellosis and tuberculosis: Case study of Pirassununga, SP, Brazil. Semina: Ciências Agrárias, v.37, n.5, Suplemento 2, p.3793-3802, 2016 b.

INLAMEA, O.F., ROCHA, A.B., FERREIRA, F., et al. Effect of vaccination in lowering bovine brucellosis in the state of Rondônia, Brazil. Semina: Ciências Agrárias, v.37, n.5, Suplemento 2, p.3493-3506, 2016.

LEAL FILHO, J.M., BOTTENE, I.F.N., MONTEIRO, L.A.R.C., et al. Control of bovine brucellosis from 1998 to 2009 in the state of Mato Grosso do Sul, Brazil. Semina: Ciências Agrárias, v.37, n.5, Suplemento 2, p.3467-3478, 2016.

LEITE, B.M. Aspectos epidemiológicos e econômicos da certificação de propriedades leiteiras como livres de brucelose e tuberculose bovina. 2012. Vii, 81f., il. Dissertação (Mestrado em Saúde Animal) - Universidade de Brasília, Brasília, 2012.

LÔBO, J.R. Análise custo-benefício da certificação de propriedades livres de tuberculose bovina. 2008. 84f. Dissertação (Mestrado em Agronegócios) - Universidade de Brasília, Brasília, 2008.

LUCERO, N.E., AYALA, S.M., ESCOBAR, G.I., et al. Brucella isolated in humans and animals in Latin America from 1968 to 2006. Epidemiol. Infect.,136, p.496-503, 2008.

MINAS, M., MINAS, A., GOURGULIANIS, K.,et al. Epidemiological and Clinical Aspects of Human Brucellosis in Central Greece. Jpn. J. Infect. Dis., 60, p.362-366, 2007.

MORALES-ESTRADA, A.I., HERNÁNDEZ-CASTRO, R., LÓPEZ-MERINO, A., etal. Isolation, identification, and antimicrobial susceptibility of Brucella spp. cultured from cows and goats manure in Mexico. Arch. Med. Vet., v.48, p.231-235, 2016.

MOTA, A.L.A.A., FERREIRA, F. FERREIRA NETO, J.S., et al. Large-scale study of herdlevel risk factors for bovine brucellosis in Brazil. ActaTropica, v.164, p.226-232, 2016. 
OCHOLI, R.A., KWAGA, J.K.P., AJOGI, I., et al. Abortion due to Brucella abortusin sheep in Nigeria. Rev. sci. tech. Off. int. Epiz.,v.24(3), p.973-979, 2005.

OIE.World Organization for Animal Health (OIE).Chapter 2.1.4. Brucellosis (Brucella abortus, B. melitensis and B. suis). In: OIE Terrestrial Manual. Paris: OIE; 2016.

OLIVEIRA, L.F., DORNELES, E.M.S., MOTA, A.L.A.A., et al. Seroprevalence and risk factors for bovine brucellosis in Minas Gerais State, Brazil.Semina: Ciências Agrárias, v.37, n.5, Suplemento 2, p.3449-3466, 2016.

PAPPAS, G., PAPADIMITRIOU, P., AKRITIDIS, N., et al. The new global map of human brucellosis. Lancet Infect Dis., v.6, p.91-99, 2006.

POESTER, F.P., GONÇALVES, V.S.P., LAGE, A.P. Brucellosis in Brazil. Veterinary Microbiology, 90, p.55-62, 2002.

RAMOS, T.R.R., PINHEIRO JUNIOR, J.W., SOBRINHO, P.A.M., et al. Epidemiological Aspects of an Infection by Brucella abortus in Risk Occupational Groups in the Microregion of Araguaína, Tocantins. The Brazilian Journal of Infectious Diseases, 12(2), p.133-138, 2008.

SAMARTINO, L.E. Brucellosis in Argentina. Veterinary Microbiology, 90, p.71-80, 2002.

SANTOS, H.P., TEIXEIRA, W.C., OLIVEIRA, M.M.M., et al. Brucelose bovina e humana diagnosticada em matadouro municipal de São Luís - MA, Brasil. Ciênc. Vet. Tróp.,v.10, $\mathrm{n}^{\circ} 2 / 3$, p.86-94, 2007.

SANTOS, R.L., MARTINS, T.M., BORGES, A.M., et al. Economic losses due to bovine brucellosis in Brazil. Pesq. Vet. Bras.,33(6), p.759-764, 2013.

SELEEM, M.N., BOYLE, S.M., SRIRANGANATHAN, N. Brucellosis: A re-emerging zoonosis. Veterinary Microbiology, 140, p.392-398, 2010.

SOLER-LLORÉNS, P.F., QUANCE, C.R., LAWHON, S.D., et al. A Brucella spp. isolate from a Pac-Man Frog (Ceratophrys ornata) Reveals Characteristics Departing from Classical Brucellae. Front. Cell. Infect. Microbiol., 6:116. doi: 10.3389/fcimb.2016.00116. 
TENÓRIO, T.G.S., MELO, L.E.H., MOTA, R.A., et al. Pesquisa de Fatores de Risco para a Brucelose Humana Associados à Presença de Brucelose Bovina no Município de Correntes, Estado de Pernambuco, Brasil. Arq. Inst. Biol., v.75, n.4, p.415-421, 2008.

USDA-APHIS 2012. October 2012. Brucellosis National Surveillance Plan.Centers for Epidemiology and Animal Health / National Surveillance Unit.<www.aphis.usda.gov> Acesso em 10 out 2016.

ZINSSTAG, J., DEAN, A., BALJINNYAM, Z., et al. Brucellosis Surveillance and Control: a Case for One Health. In: ZINSSTAG, J., SCHELLING, E., WALTNER-TOEWS, D., et al. One Health: The Theory and Practice of Integrated Health Approaches. CCAB International 2015, p.153-162. 


\section{CAPÍTULO II}

(escrito na forma de artigo para publicação)

\section{PREVALÊNCIA E FATORES DE RISCO DA BRUCELOSE BOVINA NO DISTRITO FEDERAL, BRASIL, 2015.}

\section{INTRODUÇÃO}

O Distrito Federal possui uma área territorial de 5.779,999 $\mathrm{Km}^{2}$, correspondente a aproximadamente $0,1 \%$ do território nacional. Seguindo a tendência de redução da população rural observada em todo o país, a população rural do Distrito Federal vem sofrendo uma diminuição significativa, tendo atualmente, domiciliada na área rural, apenas 3,4\% de toda a sua população (IBGE 2016a). Isso se reflete também na bovideocultura da região, que vem apresentando, desde 2013, uma diminuição anual de aproximadamente 4\% de cabeças de bovinos e bubalinos ${ }^{1}$.

Na pecuária do Distrito Federal, destaca-se a avicultura industrial, cujas exportações possuem maior impacto no PIB do agronegócio da região. Apesar da pequena dimensão da bovinocultura do Distrito Federal, a produção leiteira gerou, em 2015, um valor de produção total de R \$27,8 milhões (IBGE 2016b).

A brucelose é uma doença infectocontagiosa provocada por bactérias do gênero Brucella. Das espécies de Brucella conhecidas, a B. melitensis, B. suis e B. abortus, que acometem principalmente pequenos ruminantes, suínos e bovídeos, respectivamente, são consideradas altamente patogênicas e importantes zoonoses. Essas espécies de Brucella são as de maior interesse para a Defesa Agropecuária, passíveis de aplicação de medidas de defesa sanitária animal e estão relacionadas na Lista de Doenças de Notificação Obrigatória, atualizada em legislação específica (BRASIL, 2013), sendo a brucelose bovina a mais prevalente e mais importante para o Brasil. A brucelose bovina, alvo do presente estudo, causa principalmente infertilidade e aborto no final da gestação, acarretando importantes perdas econômicas e na produtividade do rebanho (BRASIL, 2004).

No ano de 2003, a Secretaria de Agricultura, Abastecimento e Desenvolvimento Rural do Distrito Federal (Seagri) realizou estudo transversal por amostragem da brucelose bovina

\footnotetext{
${ }^{1}$ Informação do Núcleo de Febre Aftosa da Secretaria de Agricultura, Abastecimento e Desenvolvimento Rural do Distrito Federal.
} 
no Distrito Federal, com o objetivo de conhecer a situação real da doença no seu território, identificar fatores de risco ligados à presença da doença e fornecer subsídios para a gestão estratégica do programa distrital. Foram amostrados 2.019 animais em 278 propriedades, e a prevalência estimada de focos foi de 2,5\% [IC 95\%: 1,0 - 5,1\%] e de 0,16\% [IC 95\%: 0,04$0,28 \%$ ] em animais. A pequena quantidade de focos e de animais positivos não permitiu a identificação de fatores de risco associados à presença da doença (GONÇALVES et al., 2009).

Com os resultados do estudo indicando prevalência baixa para a brucelose bovina e sem sucesso na análise de fatores de risco, a Seagri continuou a seguir, sem particularidades locais, as estratégias preconizadas pelo Programa Nacional de Controle e Erradicação da Brucelose e Tuberculose Animal - PNCEBT, que são: vacinação compulsória de bezerras entre três e oito meses de idade com a vacina B19, controle do trânsito de animais destinados à reprodução e eliminação de animais positivos aos testes de diagnóstico, sem a obrigatoriedade de saneamento em todos os bovídeos existentes na propriedade foco (BRASIL, 2004).

Apesar de uma tendência de aumento nos índices de cobertura de vacinação contra brucelose, esses são historicamente baixos no Distrito Federal, tendo atingido, no primeiro semestre de 2016, uma média de $37 \%$ de vacinação em propriedades e em animais ${ }^{2}$. Os dados de notificação compulsória de brucelose bovina indicam que ocorreram no DF 11 focos no ano de 2012, 10 focos em 2013 e novamente 10 focos em 2014. Em 2015, ano em que o presente estudo foi conduzido, foram notificados apenas dois focos de brucelose bovina ${ }^{3}$. Com exceção de duas propriedades, que tiveram notificação de focos por dois anos consecutivos, os demais focos registrados foram em propriedades diferentes.

Considerando as baixas coberturas vacinais registradas, a baixa adesão à certificação de propriedades livres ou monitoradas, o número de focos notificados sugerindo uma incidência média mensal constante e o fato de que uma pequena parcela dos bovinos existentes é submetida a exames diagnósticos anualmente, foi observado que o programa necessitava de medidas diferenciadas para ser mais dinâmico. Assim, como parte de um projeto cooperativo entre o Ministério da Agricultura, Pecuária e Abastecimento - Mapa e a

\footnotetext{
${ }^{2}$ Informação do Núcleo de Epidemiologia e Trânsito da Secretaria de Agricultura, Abastecimento e Desenvolvimento Rural do Distrito Federal.

${ }^{3}$ Informação do Núcleo de Brucelose e Tuberculose da Secretaria de Agricultura, Abastecimento e Desenvolvimento Rural do Distrito Federal.
} 
Seagri, o Laboratório de Epidemiologia e Bioestatística da Universidade de São Paulo (LEB/VPS/FMVZ/USP) e o Laboratório de Epidemiologia Veterinária da Universidade de Brasília (Epiplan/FAV/UnB), foi realizado novo estudo transversal da situação da brucelose bovina no Distrito Federal, objetivando estimar a prevalência e identificar possíveis fatores de risco associados à doença, visando subsidiar a escolha das melhores estratégias para o controle da doença e, comparando com os resultados do inquérito realizado em 2003, promover correções no programa, a fim de otimizar os investimentos públicos no controle da brucelose.

\section{MATERIAL E MÉTODOS}

O trabalho de campo foi realizado entre os meses de junho e dezembro de 2015 , e consistiu em visitas às propriedades selecionadas aleatoriamente para verificar a adesão do produtor ao estudo, realização dos exames diagnósticos e aplicação de questionário epidemiológico. A população alvo do estudo transversal foi constituída por todas as propriedades com explorações de bovinos, e que possuíam fêmeas em idade reprodutiva. A base de dados utilizada para amostragem foi o cadastro de propriedades mantido pela Seagri.

A população alvo foi divida em duas subpopulações, de acordo com o tamanho dos rebanhos. A análise da base de dados utilizada para amostragem revelou que aproximadamente $75 \%$ das propriedades com bovinos no Distrito Federal tinham menos de 15 fêmeas em idade reprodutiva e representavam aproximadamente $25 \%$ do total de fêmeas em idade reprodutiva existentes no DF. Consequentemente, $25 \%$ das propriedades com bovinos possuíam 15 ou mais fêmeas e albergavam $75 \%$ das fêmeas em idade reprodutiva no DF. Assim, a primeira subpopulação, de rebanhos pequenos, foi formada por propriedades com até 15 (quinze) fêmeas com mais de 24 (vinte e quatro) meses, isto é, em idade reprodutiva. A segunda subpopulação, de rebanhos maiores, foi constituída por propriedades com 15 (quinze) ou mais fêmeas em idade reprodutiva.

$\mathrm{O}$ estudo amostral foi então realizado em duas etapas. Na primeira etapa, foram selecionadas, para cada subpopulação e de forma aleatória, um número pré-estabelecido de unidades primárias de amostragem (propriedades com fêmeas em idade reprodutiva). $\mathrm{Na}$ segunda etapa, foram selecionadas, de forma aleatória, um número pré-estabelecido de fêmeas em idade reprodutiva em cada rebanho (unidades secundárias de amostragem). 
Os tamanhos amostrais das unidades primárias de amostragem para cada subpopulação foram calculados utilizando a ferramenta Epitools ${ }^{\circledR}$. Para a subpopulação de rebanhos pequenos, foram utilizados os seguintes parâmetros: prevalência estimada de 1,5\%, nível de confiança de 95\%, erro amostral de 1,5\%, em uma população de 2.082 propriedades, de acordo com o cadastro de propriedades da Seagri. Para a seleção de propriedades com rebanhos grandes, os seguintes parâmetros foram utilizados: prevalência estimada de 2,5\%, nível de confiança de $95 \%$, erro amostral de 2,5\%, em uma população cadastrada de 645 propriedades. O cálculo gerou um número mínimo a selecionar de 122 propriedades com rebanhos grandes e 226 com rebanhos pequenos.

Apesar da impossibilidade de analisar fatores de risco para a brucelose bovina no Distrito Federal no estudo realizado em 2003, rebanhos grandes são amplamente relatados na literatura como fator de risco para a doença no Brasil (MOTA et al., 2016). Por isso, optou-se pela estimativa de prevalência maior para rebanhos maiores neste estudo.

As unidades primárias de amostragem no Distrito Federal de cada uma das subpopulações definidas foram distribuídas de forma ponderada entre as áreas de jurisdição dos cinco escritórios que a Seagri possui. As propriedades sorteadas que não puderam ser amostradas foram substituídas por outra, localizada na mesma região e pertencente ao mesmo estrato.

Para o cálculo do número de unidades secundárias de amostragem em cada propriedade amostrada, simulou-se no programa Epitools ${ }^{\circledR}$ o número mínimo de animais que deveriam ser testados para ser alcançada uma sensibilidade mínima de rebanho de 95\%. Para tanto, foram adotados os valores de $95 \%$ e 99,5\%, respectivamente, para a sensibilidade e especificidade do protocolo de testes utilizado (FLETCHER et al., 1988) e estimada uma prevalência intra-rebanho de $20 \%$. Assim, nas propriedades com menos de 10 fêmeas com mais de 24 meses, foi coletado sangue de todas as fêmeas. Em propriedades com 11 a 99 fêmeas em idade reprodutiva, foram coletadas 10 amostras de sangue. Nas propriedades com 100 ou mais fêmeas, foram coletadas 15 amostras de sangue. Foram excluídas das amostras as fêmeas em período de peri-parto (15 dias antes ou após o parto).

Para o diagnóstico da brucelose bovina, os soros dos animais foram submetidos a um protocolo de testes em série, como preconizado pelo PNCEBT (BRASIL, 2004). Como teste de triagem, foi utilizado o teste do Antígeno Acidificado Tamponado (AAT), realizado no próprio laboratório da Seagri. Os soros que reagiram positivamente a esse teste foram 
encaminhados ao laboratório de referência do Mapa (LANAGRO) para o teste confirmatório, 2-Mercaptoetanol (2-ME). A propriedade foi considerada foco de brucelose quando pelo menos um animal reagiu positivamente aos dois testes de diagnóstico.

Os cálculos de prevalência em propriedades e em animais foram feitos de forma ponderada, de acordo com o preconizado por DOHOO et al. (2010). Para o cálculo da prevalência de focos de brucelose, foi calculado o peso de cada propriedade no Distrito Federal, seguindo a seguinte equação:

$$
P_{1}=\frac{\text { número de propriedades existentes na subpopulação }}{\text { número de propriedades amostradas na subpopulação }}
$$

Para o cálculo da prevalência de brucelose em animais, foi utilizada a seguinte equação:

$P_{2}=\frac{f \text { êmeas } \geq 24 \text { meses na propriedade }}{f \text { êmeas } \geq 24 \text { meses amostradas na propriedade }} \times \frac{f \text { fêmeas } \geq 24 \text { meses na subpopulação }}{\text { fêmeas } \geq 24 \text { meses nas propriedades amostradas }}$

Durante as atividades de colheita de material e realização de exames, um questionário epidemiológico foi aplicado em cada propriedade amostrada. Esse questionário foi composto de variáveis relativas às características produtivas da propriedade e de práticas de manejo que podem ter impacto na saúde pública e nas formas de organização da vigilância em saúde animal.

Os dados foram armazenados usando um banco online, e analisados com auxílio do programa STATA 13. Inicialmente, foi realizada uma análise descritiva a partir dos dados armazenados, para melhor caracterização da bovinocultura no Distrito Federal e práticas de manejo dos produtores da região. Nesta etapa, dados da Seagri também foram utilizados, para melhor fundamentação das informações obtidas e verificação da consistência dos dados. Para a análise de fatores de risco para a brucelose bovina no DF, inicialmente, foi feita uma análise exploratória das seguintes variáveis em relação a presença da brucelose bovina nas propriedades, usando o teste do qui-quadrado:

- Tipo da exploração (corte, leite ou mista);

- Tipo de criação (extensivo, semi-confinado ou confinado);

- Classificação da propriedade (rural clássica, aldeia indígena, assentamento ou periferia urbana); 
- Número de ordenhas por dia (não ordenha, 1 ordenha, 2 ou 3 ordenhas) e tipo da ordenha (não ordenha, manual, mecânica ao pé ou mecânica em sala de ordenha);

- Uso de inseminação artificial (não usa, usa inseminação artificial e touro, só usa inseminação artificial);

- Raça predominante de bovinos (zebu, europeu de leite, europeu de corte, mestiço, outras raças);

- Presença de outros animais domésticos na propriedade (ovinos/capinos, equídeos, suídeos, aves comerciais, cães e gatos) e de animais de vida livre (sim ou não); e, se sim, quais espécies de animais de vida livre (cervídeos, capivaras, felídeos, marsupiais, macacos ou outros);

- Aquisição de bovinos nos últimos 2 anos (sim ou não) e se introduziu fêmeas ou machos bovinos com finalidade de reprodução (sim ou não).Se o produtor respondesse sim para qualquer uma das últimas duas perguntas, especificar a procedência dos animais (exposição, leilão/feira, comerciante de gado ou outras fazendas);

- Venda de fêmeas ou machos para reprodução (sim ou não). Se vender, qual o destino dos animais (exposição, leilão/feira, comerciante de gado ou outras fazendas);

- Local de abate das fêmeas e machos adultos (na própria fazenda, em estabelecimento com ou sem inspeção veterinária ou não abate);

- Aluguel de pasto;

- Pastos em comum com outras propriedades;

- Compartilha de outros itens com outras propriedades (sim ou não). Se compartilhar, que tipo de item (insumos, equipamentos ou funcionários);

- Existência na propriedade de áreas alagadiças às quais o gado tem acesso;

- Entrega de leite (cooperativa, laticínio, direto ao consumidor ou não entrega);

- Resfriamento do leite (sim ou não). Se resfriar, como faz (em resfriador ou tanque de expansão próprio ou coletivo);

- Entrega do leite a granel; 
- Produção de queijo, manteiga ou outro produto lácteo na propriedade (sim ou não). E se produzir, com que finalidade (consumo próprio ou venda);

- Consumo de leite cru ou derivado lácteo produzido com leite cru;

- Assistência veterinária (possui ou não). Se sim, de que tipo (veterinário da cooperativa ou particular);

- Alimentação de bovinos com soro de leite bovino;

- Número de bovinos comprados no último ano, e de quantas fazendas;

- Abortos de vacas no último ano (sim, não ou não sabe);

- Destinação do feto abortado (enterra/joga em fossa/queima, alimenta porco/cão ou não faz nada);

- Realização de teste para diagnóstico de brucelose e qual a frequência;

- Se o produtor vacina contra a brucelose com a B19;

- Se a vacina contra a brucelose é bem conservada e se a vacinação é corretamente executada;

- Compartilhamento de aguadas/bebedouros com animais de outras propriedades;

- Existência nas propriedades de área para pouso de boiada em trânsito;

- Existência na propriedade de área onde o gado permanece concentrado durante o dia ou à noite (não, palafita, ou outro tipo);

- Existência de piquete separado para fêmeas na fase de parto e/ou pós-parto.

Após esta análise exploratória dos dados, procedeu-se a regressão logística múltipla com todas as variáveis que apresentaram um valor $\mathrm{p} \leq 0,20$. O método utilizado para compor o modelo de regressão logística foi o de eliminação hierárquica (Hierarchical backward elimination) para obtenção de um modelo logístico reduzido pela retirada progressiva do modelo inicial completo de variáveis sem significância estatística, restando somente aquelas com um valor-p $\leq 0,05$. Foi utilizado o formato design-based no modelo, que considera o 
peso de cada propriedade amostrada nas duas subpopulações definidas para o estudo (HOSMER et al., 2013).

\section{RESULTADOS}

No presente estudo foram amostradas 344 propriedades, das quais 229 possuíam rebanhos considerados pequenos e 115 eram rebanhos grandes, como descritos na Tabela 1.

Tabela1. Dados censitários da população bovina do Distrito Federal, por tamanho de rebanho.

\begin{tabular}{ccc|cc}
\hline \multirow{2}{*}{$\begin{array}{c}\text { Tamanho de } \\
\text { rebanho* }\end{array}$} & \multicolumn{2}{c|}{$\begin{array}{c}\text { Rebanhos com atividade } \\
\text { reprodutiva }\end{array}$} & \multicolumn{2}{c}{ Fêmeas com $\geq 24$ meses } \\
\cline { 2 - 5 } & Existentes & Amostrados & Existentes & Amostradas \\
\hline Pequeno & 2082 & 229 & 10336 & 1043 \\
Grande & 645 & 115 & 33337 & 1204 \\
\hline TOTAL & 2727 & 344 & 43673 & 2247 \\
\hline
\end{tabular}

* Rebanhos pequenos apresentavam menos de 15 fêmeas com mais de 24 meses. Rebanhos grandes apresentavam 15 ou mais fêmeas com mais de 24 meses.

As propriedades amostradas possuíam majoritariamente poucas fêmeas com mais de 24 meses, como pode ser observado na figura 2. Cerca de $75 \%$ das propriedades amostradas na subpopulação de rebanhos pequenos e na subpopulação de rebanhos grandes possuíam, respectivamente, até 8 e até 55 fêmeas em idade reprodutiva. Apenas 11 propriedades possuíam mais de 100 fêmeas em idade reprodutiva, e a maior propriedade trabalhada tinha 983 fêmeas com mais de 24 meses.

Figura 2. Boxplot do $\mathrm{n}^{\circ}$ de fêmeas com idade acima de 24 meses por propriedade amostrada por subpopulação no Distrito Federal, 2015.

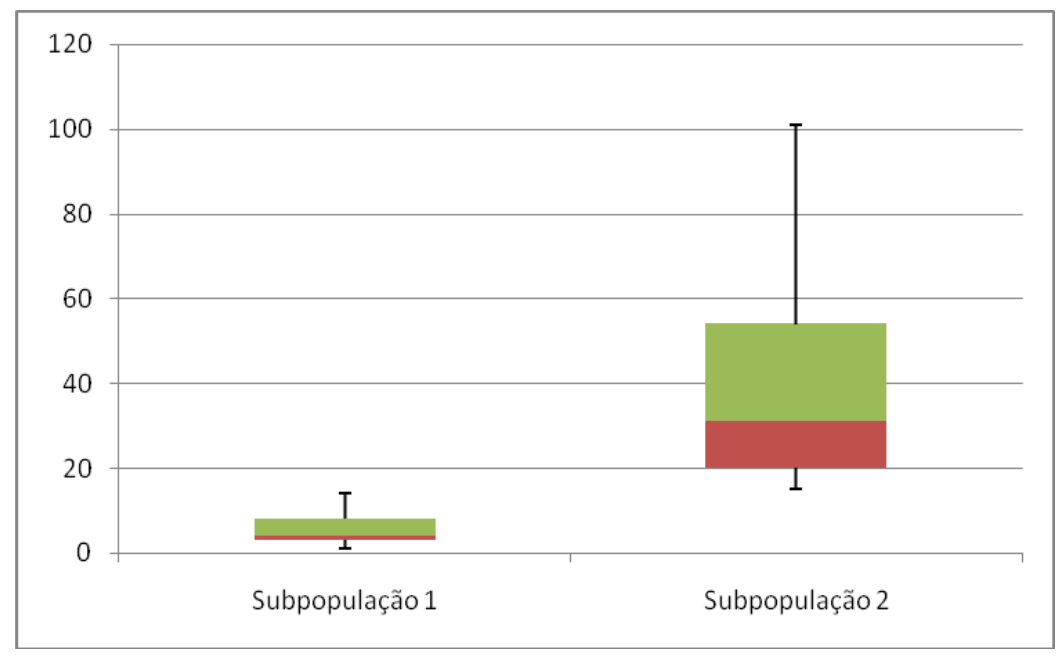


No estudo, 12 propriedades foram consideradas focos de brucelose, com um total de 21 animais positivos. Dos 12 focos, apenas três apresentaram mais de um animal com resultado positivo. Dessas três propriedades, duas pertenciam à subpopulação de rebanhos considerados grandes.

O mapa abaixo demonstra a dispersão geográfica das propriedades positivas no estudo e não sugere a existência de aglomerados de focos, indicando que a doença, apesar de apresentar baixa prevalência, está dispersa em todo o território estudado.

Figura 3. Mapa da distribuição espacial de focos de brucelose, 2015.

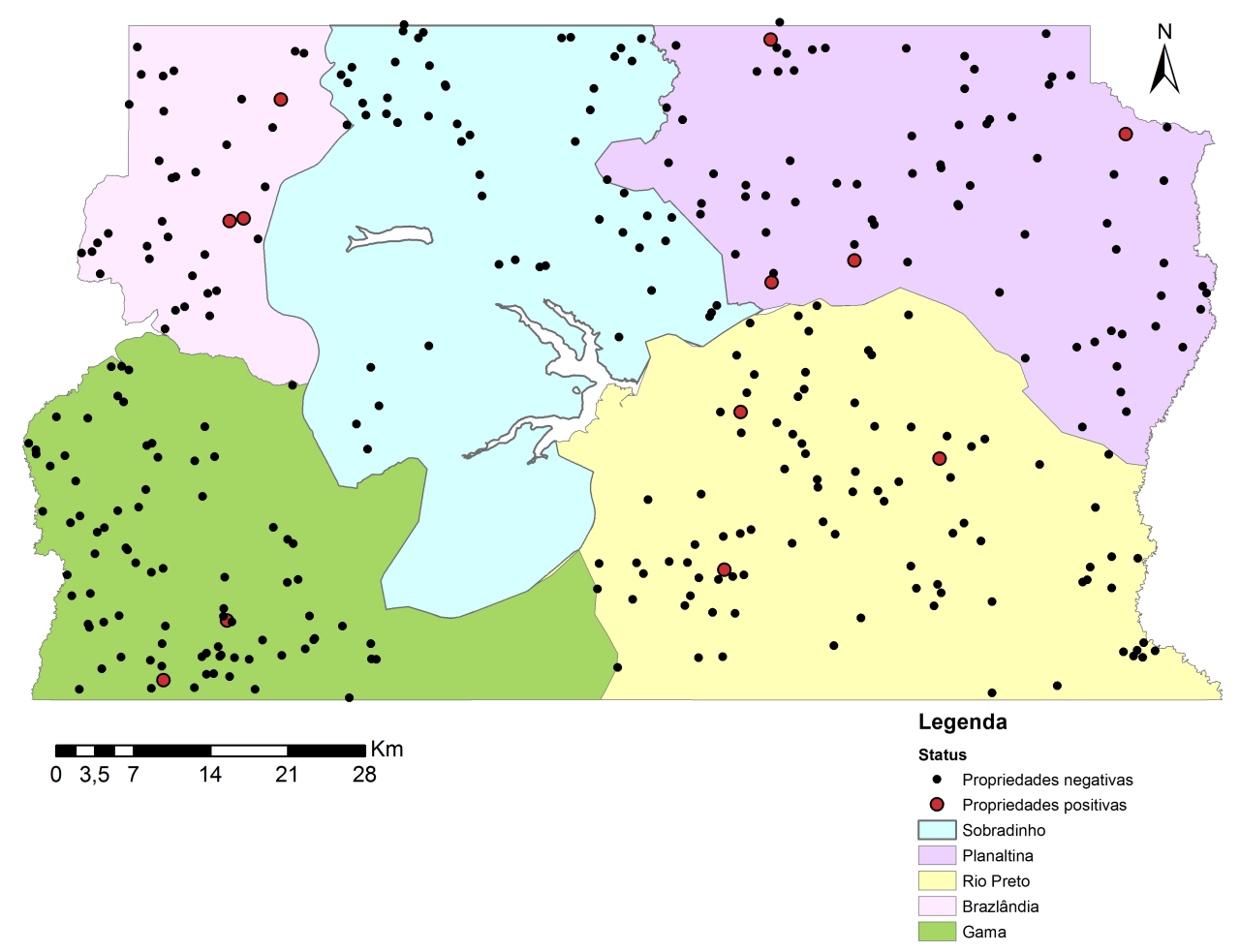

A prevalência estimada de focos de brucelose no Distrito Federal foi de 3,1\% [1,31\% 4,9\%] (Tabela 2). Nota-se que apesar de haver sobreposição dos intervalos de confiança das prevalências de cada tipo de rebanho, a prevalência estimada de brucelose em rebanhos grandes foi maior que em propriedades com rebanhos pequenos. 
Tabela 2. Prevalência aparente de rebanhos para brucelose bovina no Distrito Federal, por tamanho de rebanho.

\begin{tabular}{cccc}
\hline Tamanho de & No. de rebanhos & Prevalência aparente (\%) & Intervalo de confiança \\
rebanho* & positivos & (95\%)
\end{tabular}

\begin{tabular}{cccc}
\hline Pequeno & 5 & 2,18 & {$[0,71-5,02]$} \\
Grande & 7 & 6,08 & {$[2,48-12,13]$} \\
\hline Total & 12 & 3,1 & {$[1,31-4,9]$}
\end{tabular}

* Rebanhos pequenos apresentavam menos de 15 fêmeas com mais de 24 meses. Rebanhos grandes apresentavam 15 ou mais fêmeas com mais de 24 meses

A tabela 3 apresenta a prevalência de brucelose em animais no Distrito Federal, que foi igual a $0,93 \%$ [0,16\% - 1,71\%]. Assim como observado nas prevalências de focos de brucelose, a prevalência média de brucelose em animais foi maior em rebanhos grandes, quando comparada aos rebanhos pequenos. Porém, também houve sobreposição dos intervalos de confiança das prevalências de cada tipo de rebanho.

Tabela 3. Prevalência de brucelose bovina em vacas com 24 meses ou mais no Distrito Federal, por tamanho de rebanho.

\begin{tabular}{cccc}
\hline $\begin{array}{c}\text { Tamanho de } \\
\text { rebanho* }\end{array}$ & $\begin{array}{c}\text { No. de animais } \\
\text { positivos }\end{array}$ & Prevalência aparente (\%) & $\begin{array}{c}\text { Intervalo de confiança } \\
(95 \%)\end{array}$ \\
\hline Pequeno & 7 & 0,59 & {$[0,01-1,18]$} \\
Grande & 14 & 1,04 & {$[0,03-2,04]$} \\
\hline Total & 21 & 0,93 & {$[0,16-1,71]$}
\end{tabular}

* Rebanhos pequenos apresentavam menos de 15 fêmeas com mais de 24 meses. Rebanhos grandes apresentavam 15 ou mais fêmeas com mais de 24 meses

Com os valores médios de prevalência de brucelose em propriedades no Distrito Federal e seus respectivos intervalos de confiança, foi possível estimar o número provável de propriedades infectadas no Distrito Federal, descritos na tabela 4. 
Tabela 4. Prevalências e número provável de propriedades infectadas no Distrito Federal, por tamanho de rebanho.

\begin{tabular}{|c|c|c|c|c|c|c|c|}
\hline \multirow{2}{*}{$\begin{array}{l}\text { Tamanho de } \\
\text { rebanho* }\end{array}$} & \multirow{2}{*}{$\begin{array}{l}\text { Propriedades } \\
\text { cadastradas }\end{array}$} & \multicolumn{3}{|c|}{ Prevalência } & \multicolumn{3}{|c|}{$\begin{array}{c}\text { Número provável de } \\
\text { propriedades infectadas }\end{array}$} \\
\hline & & $\begin{array}{l}\text { Limite } \\
\text { inferior }\end{array}$ & $\begin{array}{l}\text { Valor } \\
\text { médio }\end{array}$ & $\begin{array}{c}\text { Limite } \\
\text { Superior }\end{array}$ & $\begin{array}{l}\text { Limite } \\
\text { inferior }\end{array}$ & $\begin{array}{l}\text { Valor } \\
\text { médio }\end{array}$ & $\begin{array}{c}\text { Limite } \\
\text { Superior }\end{array}$ \\
\hline Pequeno & 2.082 & 0,0071 & 0,0218 & 0,0502 & 15 & 45 & 105 \\
\hline Grande & 645 & 0,0248 & 0,0608 & 0,1213 & 16 & 39 & 78 \\
\hline
\end{tabular}

A análise exploratória dos dados evidenciou algumas características importantes da bovinocultura no Distrito Federal e práticas de manejo dos produtores da região. O índice baixo de movimentação animal fica evidenciado quando aproximadamente $51 \%$ dos produtores entrevistados relataram não ter adquirido nenhum animal nos últimos dois anos. Dos produtores que declararam ter adquirido animais, quase $80 \%$ compraram até 10 animais, oriundos em sua maioria de outras fazendas. Como demonstrado na tabela 5, observa-se uma tendência de produtores com rebanhos maiores movimentarem mais animais.

Tabela 5. Número de produtores que adquiriram animais em dois anos, por tamanho de rebanho.

\begin{tabular}{cccc}
\hline $\begin{array}{c}\text { Tamanho de } \\
\text { rebanho* }\end{array}$ & Não adquiriram & Adquiriram & Total \\
\hline $\begin{array}{c}\text { Pequeno } \\
\text { Grande }\end{array}$ & 123 & 106 & 229 \\
\hline Total & 176 & 62 & 115 \\
\hline
\end{tabular}

* Rebanhos pequenos apresentavam menos de 15 fêmeas com mais de 24 meses. Rebanhos grandes apresentavam 15 ou mais fêmeas com mais de 24 meses

A tendência de produtores com rebanhos maiores adquirirem mais animais fica mais evidenciada nas propriedades com tipo de criação semiconfinado, como pode ser observado na tabela abaixo. 
Tabela 6. Número de produtores que adquiriram animais em dois anos, por tipo de criação e tamanho de rebanho.

\begin{tabular}{ccccccc}
\hline $\begin{array}{c}\text { Tamanho de } \\
\text { rebanho* }\end{array}$ & $\begin{array}{c}\text { Extensivo } \\
\text { adquiriram }\end{array}$ & Adquiriram & $\begin{array}{c}\text { Semiconfinado } \\
\text { Não } \\
\text { adquiriram }\end{array}$ & Adquiriram & $\begin{array}{c}\text { Confinado } \\
\text { adquiriram }\end{array}$ & Adquiriram \\
\hline Pequeno & 69 & 53 & 52 & 53 & 2 & 0 \\
Grande & 23 & 19 & 29 & 43 & 1 & 0 \\
\hline Total & 92 & 72 & 81 & 96 & 3 & 0
\end{tabular}

* Rebanhos pequenos apresentavam menos de 15 fêmeas com mais de 24 meses. Rebanhos grandes apresentavam 15 ou mais fêmeas com mais de 24 meses

Sobre o trânsito interestadual, em todo o ano de 2015, as propriedades do Distrito Federal adquiriram 70.336 bovinos de apenas 71 municípios diferentes, bem concentrados e regionalizados. Dos municípios citados, 75\% enviaram menos de 130 animais. Como demonstrado no mapa abaixo, os bovinos destinados ao Distrito Federal são oriundos principalmente de municípios do entorno de Goiás e regiões noroeste, norte e nordeste de Minas Gerais, nessa ordem, de acordo com os dados de trânsito de barreiras fixas e móveis da Seagri ${ }^{4}$.

\footnotetext{
${ }^{4}$ Informação do Núcleo de Epidemiologia e Trânsito da Secretaria de Agricultura, Abastecimento e Desenvolvimento Rural do Distrito Federal.
} 
Figura 4. Mapa do trânsito de bovinos destinados ao Distrito Federal, 2015.

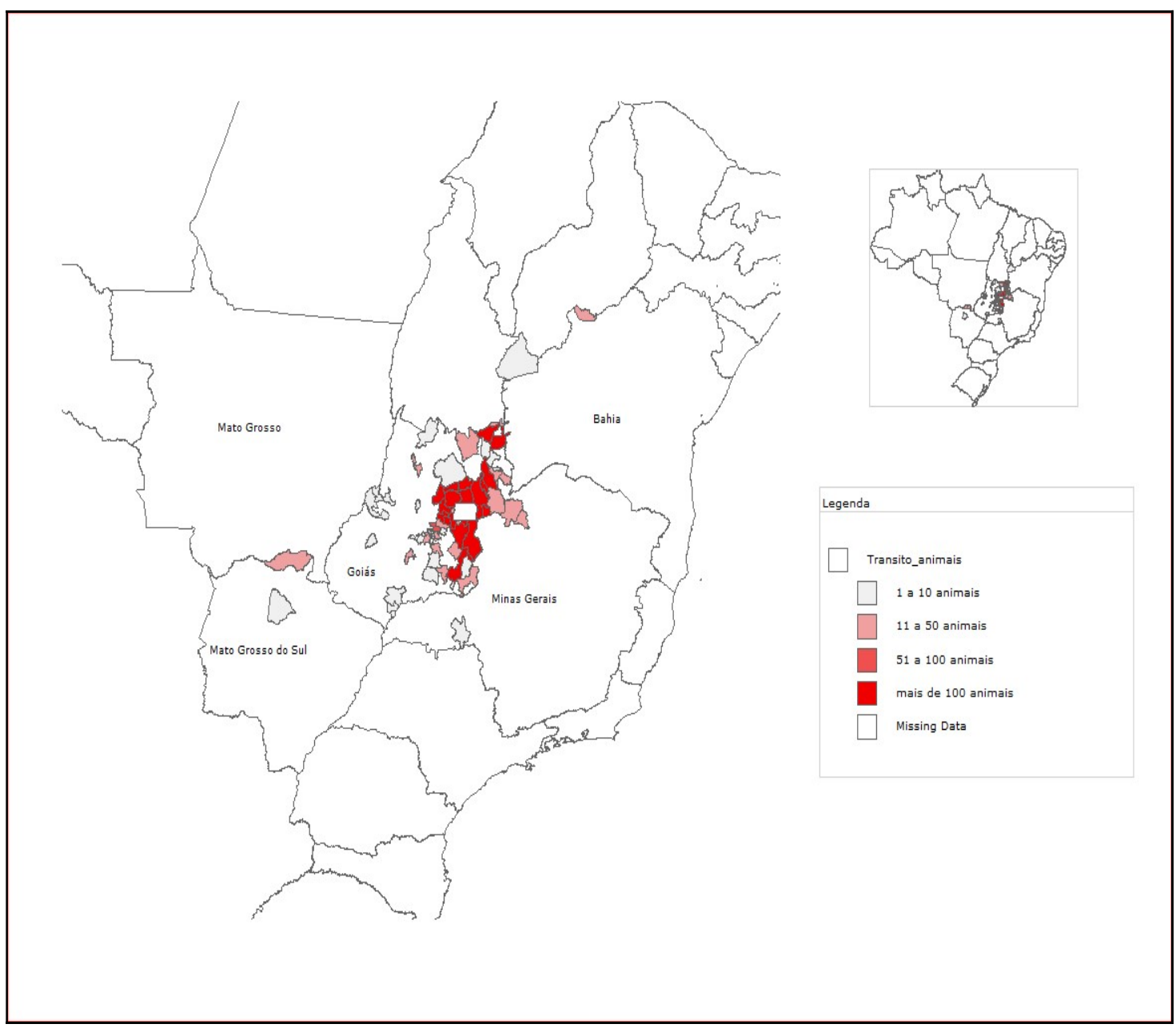

Como pode ser observado nas tabelas 7 e 8 , apesar de mais de $70 \%$ dos produtores terem declarado que vacinam bezerras utilizando a B19, das fêmeas testadas para brucelose, mais de $60 \%$ não tinham a marca de vacinação, como preconizado pelo PNCEBT e em Decreto Distrital (DISTRITO FEDERAL, 2015). A quantidade de fêmeas não vacinadas foi proporcionalmente maior em propriedades com rebanhos pequenos. 
Tabela 7. Número de produtores que declararam vacinar as fêmeas contra brucelose utilizando a B19, por tamanho de rebanho.

\begin{tabular}{cccc}
\hline $\begin{array}{c}\text { Tamanho de } \\
\text { rebanho* }\end{array}$ & Não vacinam & Vacinam & Total \\
\hline Pequeno & 84 & 145 & 229 \\
Grande & 14 & 101 & 115 \\
\hline Total & 98 & 246 & 344
\end{tabular}

* Rebanhos pequenos apresentavam menos de 15 fêmeas com mais de 24 meses. Rebanhos grandes apresentavam 15 ou mais fêmeas com mais de 24 meses

Tabela 8. Frequência de fêmeas vacinadas contra a brucelose, por tamanho de rebanho.

\begin{tabular}{ccccc}
\hline Tamanho de & \multicolumn{2}{c}{ Não vacinadas } & \multicolumn{2}{c}{ Vacinadas } \\
rebanho* & $\mathrm{N}$ & $\%$ & $\mathrm{~N}$ & $\%$ \\
\hline Pequeno & 744 & 71,26 & 300 & $\mathbf{2 8 , 7 4}$ \\
Grande & 616 & $\mathbf{5 1 , 2 1}$ & 587 & 48,79 \\
\hline Total & $\mathbf{1 3 6 0}$ & $\mathbf{6 0 , 5 3}$ & $\mathbf{8 8 7}$ & $\mathbf{3 9 , 4 7}$
\end{tabular}

* Rebanhos pequenos apresentavam menos de 15 fêmeas com mais de 24 meses. Rebanhos grandes apresentavam 15 ou mais fêmeas com mais de 24 meses

Mais de $80 \%$ dos produtores relataram não fazer testes de brucelose no rebanho. Assim como no caso da vacinação contra brucelose, nota-se uma frequência maior de produtores com rebanhos pequenos que não testam para a doença.

Tabela 9. Frequência de produtores que declararam realizar testes diagnósticos para a brucelose, por tamanho de rebanho.

\begin{tabular}{ccccc}
\hline $\begin{array}{c}\text { Tamanho de } \\
\text { rebanho* }\end{array}$ & N & $\%$ & N & $\%$ \\
\hline Pequeno & 202 & 88,21 & 27 & 11,79 \\
Grande & 75 & 65,22 & 40 & 34,78 \\
\hline Total & 277 & 80,52 & 67 & 19,48
\end{tabular}

* Rebanhos pequenos apresentavam menos de 15 fêmeas com mais de 24 meses. Rebanhos grandes apresentavam 15 ou mais fêmeas com mais de 24 meses

Considerando o risco de infecção no homem, alguns dados são preocupantes: apesar de aproximadamente apenas 30\% dos produtores terem declarado entregar leite diretamente ao consumidor, a prática de resfriar o leite não é comum na região, indicando falha nas boas 
práticas de manipulação. Mais de $86 \%$ dos entrevistados não resfriam leite. O consumo de leite cru ainda acontece em $32,46 \%$ das propriedades trabalhadas.

Uma última prática de manejo interessante observada nessa primeira análise foi o fato de mais de $60 \%$ dos produtores entrevistados relatarem não fazer nada com os restos de aborto de suas vacas. Entre os produtores de rebanhos pequenos, a frequência dos que declararam não fazer nada com os restos de aborto é ainda maior, de quase $68 \%$, como pode ser observado na tabela 10. Considerando que esse é um importante fator de disseminação da doença para outros animais e até para o homem, esse dado é preocupante.

Tabela 10. Destino dos restos de aborto das vacas, por tamanho de rebanho.

\begin{tabular}{cccccc}
\hline $\begin{array}{c}\text { Tamanho de } \\
\text { rebanho* }\end{array}$ & Enterra/incinera & $\begin{array}{c}\text { Alimenta } \\
\text { porco/cão }\end{array}$ & $\begin{array}{c}\text { Não faz } \\
\text { nada }\end{array}$ & $\begin{array}{c}\text { Não } \\
\text { respondeu }\end{array}$ & Total \\
\hline $\begin{array}{c}\text { Pequeno } \\
\text { Grande }\end{array}$ & 58 & 2 & 155 & 14 & 229 \\
\hline Total & 107 & 3 & 57 & 6 & 115 \\
\hline
\end{tabular}

* Rebanhos pequenos apresentavam menos de 15 fêmeas com mais de 24 meses. Rebanhos grandes apresentavam 15 ou mais fêmeas com mais de 24 meses

Após essa análise exploratória dos dados, foi feita a análise univariada das variáveis de interesse, quanto à presença de brucelose no rebanho. Os resultados podem ser visualizados na tabela 4. A variável "tipo da exploração" não apontou nenhuma tipologia produtiva associada a um maior risco de apresentar brucelose bovina, apesar de estudos em outros estados terem demonstrado uma prevalência maior da doença em rebanhos de corte (ROCHA et al., 2009; VILLAR et al., 2009).

Para a variável "tipo de criação" optou-se por unir as categorias "confinado" e "semiconfinado", já que sistemas de criação de confinamento ou semi-confinamento já foram descritos como fator de risco para a doença (AZEVEDO et al., 2009). Ainda assim, para o Distrito Federal, o tipo de criação não se apresentou como uma boa variável discriminante para a presença da doença na região.

Para o modelo final de regressão logística, foram selecionadas as seguintes variáveis descritas na tabela 4: "número de fêmeas no rebanho" (variável dividida em até 14 fêmeas em idade reprodutiva e 15 ou mais fêmeas), "aluguel de pasto", "aquisição de animais com finalidade reprodução", "presença de ovinos/caprinos", "presença de capivaras" e "alimenta bovinos com soro de leite bovino". 
Tabela 11. Análise univariada da associação de tipos e práticas de produção animal com a presença de brucelose no rebanho

\begin{tabular}{llll}
\hline Variável & & Casos & Con \\
\hline Tipo da exploração & Corte & 2 & 46 \\
& Leite & 7 & 173 \\
& Mista & 3 & 113
\end{tabular}

Tipo de criação

$\begin{array}{lll}\begin{array}{l}\text { Confinado ou semi- } \\ \text { confinado }\end{array} & 6 & 174 \\ \text { Extensivo } & & \\ \end{array}$

No. de fêmeas no rebanho

0.063

$\begin{array}{lll}\text { Até } 14 \text { fêmeas } & 5 & 224 \\ \text { 15oumaisfêmeas } & 7 & 108\end{array}$

Aquisição de animais nos

0.015

últimos dois anos

$\begin{array}{lll}\text { Não } & 2 & 174 \\ \text { Sim } & 10 & 158\end{array}$

Aluga pasto

$\begin{array}{lll}\text { Não } & 6 & 263 \\ \text { Sim } & 6 & 69\end{array}$

Aquisição de animais com

finalidade de reprodução

$\begin{array}{lll}\text { Não } & 2 & 225 \\ \text { Sim } & 10 & 107\end{array}$

Presença de ovinos e/ou caprinos

$\begin{array}{lll}\text { Não } & 7 & 271 \\ \text { Sim } & 5 & 61\end{array}$

Presença de capivaras

$\begin{array}{lll}\text { Não } & 6 & 230 \\ \text { Sim } & 6 & 102\end{array}$

Alimenta bovinos com soro de 0.025 leite

$\begin{array}{lll}\text { Não } & 10 & 320 \\ \text { Sim } & 2 & 12\end{array}$

${ }^{1}$ valor-p no resultado do teste de qui-quadrado. 
Apenas a variável "aquisição de animais com finalidade de reprodução" permaneceu no modelo final de regressão logística, com um valor de $\mathrm{p}<0,05$.

Tabela 12. Modelo de regressão logística usando método design-based.

\begin{tabular}{cccc}
\hline Variável & $\begin{array}{c}\text { Odds } \\
\text { Ratio }\end{array}$ & $\begin{array}{c}\text { Intervalo de Confiança } \\
(95 \%)\end{array}$ & Valor-p \\
\hline $\begin{array}{c}\text { Aquisição de } \\
\text { animais com }\end{array}$ & 14.3 & & \\
finalidade de & & & 0.001 \\
reprodução & & & \\
\hline
\end{tabular}

O valor de Odds Ratio descrito na tabela acima indica que a compra de animais reprodutores aumenta em média a chance de o rebanho apresentar brucelose bovina em 14,3 vezes no Distrito Federal, porém com intervalo de confiança muito amplo, ou seja, com incerteza grande quanto à magnitude dessa associação.

\section{DISCUSSÃO e CONCLUSÕES}

O estudo de brucelose bovina realizado em 2003 no DF indicou uma prevalência de focos de 2,5\% [1,0-5,1\%] e de animais de 0,16\% [0,04-0,28\%] (GONÇALVES et al., 2009). Em comparação com os resultados apresentados, não é possível afirmar, com $95 \%$ de confiança, que houve diferença nos valores de prevalência de focos e de animais nos dois estudos, apesar de os valores médios de prevalência em rebanhos e em animais do presente estudo terem sido superiores (prevalência de propriedades de 3,1\% [1,31-4,9] e de animais de $0,93 \%[0,16-1,71])$.

A análise de fatores de risco confirmou que a compra de animais com finalidade de reprodução aumenta o risco de introdução da brucelose em um rebanho sadio (BRASIL, 2006). Este resultado é coerente com os achados de Mota et al. (2016), em estudo sobre os fatores de risco para brucelose bovina em 14 unidades federativas do Brasil, que identificou que as principais variáveis associadas à presença da doença foram aquisição de reprodutores, especialmente de comerciantes de gados e diretamente de outras fazendas, criação de animais em sistemas extensivos e quantidade de fêmeas na propriedade.

Vale salientar que o problema não é a compra de animais, atividade corriqueira para produtores rurais, mas a compra de animais sem a exigência de realização de testes de 
diagnóstico para a doença. Mais de $80 \%$ dos produtores entrevistados declararam não fazer exames para brucelose rotineiramente, e, dos que fazem, mais de $40 \%$ faz somente uma vez ao ano e cerca de $30 \%$ somente quando compra animais.

Os resultados observados reforçam a ideia de que a brucelose é um problema maior em sistemas de produção com grandes rebanhos e fluxo intenso de animais (MOTA et al., 2016). As particularidades da região em relação à bovinocultura podem explicar o fato de o Distrito Federal permanecer com prevalências baixas, mesmo estando na região Centro-Oeste, que apresentou prevalências de até $40 \%$ nos primeiros estudos realizados após a regulamentação do PNCEBT (ROCHA et al., 2009; CHATE et al., 2009; NEGREIROS et al., 2009). Ainda que os estados do Mato Grosso e Mato Grosso do Sul já tenham realizado estudos mais atualizados, evidenciando uma queda nas prevalências de focos de brucelose bovina, estas continuam altas, com valores de $24 \%$ e $30,6 \%$, respectivamente (FERREIRA NETO et al., 2016).

O Distrito Federal é caracterizado por pequenas propriedades, com pouca concentração de animais, pouco tecnificadas, trânsito de bovinos com baixa intensidade e com o trânsito interestadual de bovinos bem regionalizado, oriundos principalmente de Goiás e Minas Gerais. Goiás, como os demais estados do Centro-Oeste, apresentou, em estudo realizado em 2002, altas prevalências de focos $(17,5 \%$ [14,9\% - 20,2\%]) e de animais $(3,0 \%$ $[2,7 \%-3,3 \%]$ ) para a brucelose bovina (ROCHA et al., 2009). No caso de Minas Gerais, o último estudo demonstrou uma queda significativa nas prevalências de brucelose bovina. A prevalência de focos de brucelose bovina no estado foi de 6,04\% para 3,59\%, com o investimento em um programa de vacinação utilizando a vacina B19 (OLIVEIRA et al., 2016). Não há publicação mais recente de prevalência da brucelose bovina no estado de Goiás. Em 2015, mais de 70.000 bovinos oriundos de outros estados foram adquiridos. Considerando que o efetivo de bovinos no Distrito Federal é de pouco mais de 90.000 cabeças, pode-se dizer que o fluxo de animais não é baixo. A análise do questionário, porém, revelou que mais da metade dos produtores não adquiriram animais em dois anos. Além disso, a maioria dos produtores que adquiriram animais comprou menos de 10 bovinos. Assim, é natural supor que, embora o fluxo de animais não seja baixo, este está concentrado em poucas propriedades. Esse pequeno fluxo de trânsito de bovinos é o provável motivo para as baixas prevalências de brucelose bovina, mesmo com a dependência de municípios e regiões com prevalências mais altas, especialmente no caso de Goiás. 
Outro objetivo ao realizar esse segundo estudo de prevalência da brucelose bovina foi o de promover correções e ajustes ao programa estadual de controle da doença. As coberturas de vacinação contra brucelose bovina são historicamente baixas no Distrito Federal. Kuroda et al. (2016) alertam para a dificuldade de se estabelecer corretamente os índices de cobertura vacinal contra a brucelose bovina utilizando a vacina B19, por dois principais fatores: o primeiro é associado com o período de tempo em que as fêmeas podem ser vacinadas. $\mathrm{O}$ segundo fator é associado com as diferentes faixas etárias utilizadas por cada estado para estratificar os rebanhos. Para o controle dos animais e rebanhos vacinados contra a brucelose, o Distrito Federal utiliza a faixa etária de zero a doze meses, e a vacina só pode ser aplicada em fêmeas de três a oito meses, sugerindo que os índices oficiais de vacinação contra brucelose devem estar abaixo da realidade. Ainda assim, estão muito abaixo do recomendado pelo PNCEBT, que preconiza que as coberturas vacinais no estado sejam acima de $80 \%$.

A característica do Distrito Federal de possuir majoritariamente propriedades com rebanhos pequenos pode ser um importante obstáculo para alcançar índices altos de vacinação contra brucelose, principalmente devido aos custos inerentes a esta atividade. A maior parte das fêmeas amostradas não apresentava marca de vacinação contra brucelose, e nas propriedades de rebanhos pequenos a proporção foi ainda maior.

Ainda assim, apesar das baixas coberturas vacinais contra brucelose no Distrito Federal, o estudo atual não foi capaz de demonstrar aumento nas prevalências em focos e em animais. Gonçalves et al (2009), no estudo realizado no Distrito Federal em 2003, falava da importância de avaliar a estratégia de vacinação obrigatória de bezerras, já que mesmo uma boa cobertura vacinal provavelmente não contribuiria para diminuir uma prevalência já baixa. Os resultados desse estudo corroboram a idéia de que a estratégia de vacinação obrigatória de bezerras deve ser repensada, principalmente quando são observados índices baixos de vacinação, sem comprovação de eficácia e com altos custos ao produtor rural.

Uma medida importante para o PNCEBT é a certificação de propriedades livres ou monitoradas para a doença. Porém, essa medida é de adesão voluntária e, no Distrito Federal, apenas um produtor aderiu à certificação de sua propriedade como livre para brucelose desde o início das ações do programa distrital de controle da doença.

Leite (2012), utilizando modelos de análise custo-benefício para a certificação de dois tipos de rebanhos leiteiros como livres para brucelose e tuberculose, demonstrou que para o pequeno produtor ter o retorno do capital investido na certificação de sua propriedade como 
livre em um prazo de cinco anos, a política de indenização de $100 \%$ do valor do animal teria que ser acompanhada de outras medidas de incentivo, como o pagamento adicional por litro de leite produzido. Considerando a realidade do Distrito Federal, a demora no retorno do investimento é um importante motivo para a baixa adesão dos produtores a essa medida.

Os focos de brucelose notificados sugerem uma incidência anual constante para a doença no Distrito Federal, com exceção do ano de 2015. Estes dados são oriundos principalmente de médicos veterinários habilitados, que realizam os exames de acordo com a necessidade do produtor rural e nem sempre testam todos os animais da propriedade. Analisando os dados das propriedades que realizam os exames e as propriedades com bovinos existentes no Distrito Federal, de acordo com o banco de dados da Seagri, nota-se que, anualmente, menos de 10\% das propriedades e dos bovinos do Distrito Federal são testados para a doença.

Os números de prováveis propriedades infectadas no Distrito Federal sugerem que a quantidade de focos registrados anualmente através de vigilância passiva no Distrito Federal está abaixo da realidade. Por isso, recomenda-se aliar a busca ativa de focos baseada em análise de fatores de risco à vigilância passiva, realizando o devido saneamento em toda propriedade infectada. A vigilância ativa baseada em risco, visando especialmente propriedades com movimentação intensa de animais, principalmente animais reprodutores, seria mais eficiente na busca e eliminação de animais positivos. O número de prováveis propriedades infectadas é uma boa ferramenta de análise para que a Seagri possa avaliar sua capacidade operacional para implementar medidas de erradicação da doença. Estudos de casocontrole poderiam também ser delineados e executados, permitindo assim a identificação de mais fatores de risco, específicos para realidade local, tornando o programa estadual mais dinâmico e eficiente.

Por ultimo, os dados encontrados nesse estudo sugerem que ações de educação do produtor rural devem ser intensificadas, principalmente sobre a importância da realização de exames diagnósticos para brucelose nos animais adquiridos, especialmente reprodutores. Os dados da análise exploratória do questionário também sugerem que o produtor deve ser conscientizado sobre a importância da destinação correta dos restos de aborto para evitar a disseminação da doença na propriedade; além de evitar o consumo do leite cru, medidas importantes para evitar a exposição humana à doença. 
Avaliando a situação epidemiológica da brucelose bovina no Distrito Federal descrita nesse estudo, o Distrito Federal pode ser classificado como região de baixo risco para a brucelose bovina e deve pensar em estratégias de erradicação da doença em seu território, de acordo com as novas regras do PNCEBT. Para isso, ações de intensificação do diagnóstico da doença, aliando a vigilância passiva à busca ativa de focos, baseada em análise de fatores de risco, devem ser intensificadas. O saneamento de todo o rebanho nos focos detectados deve ser estimulado também, evitando a manutenção da doença no território. 


\section{REFERÊNCIAS BIBLIOGRÁFICAS}

ALVES, A.J.S., ROCHA, F., AMAKU, M. et al. Economic analysis of vaccination to control bovine brucellosis in the States of São Paulo and Mato Grosso, Brazil. PreventiveVeterinary Medicine, v.118, p.351-358, 2015.

AZEVEDO, S.S., FERREIRA NETO, J.S., DIAS, R.A., etal.Situação epidemiológica da brucelose bovina no Estado do Espírito Santo. Arq. Bras. Med. Vet. Zootec., v.61, supl. 1, p.19-26, 2009.

BRASIL 2004. IN n 6, de 08 de janeiro - Aprova o Regulamento Técnico do Programa Nacional de Controle e Erradicação da Brucelose e Tuberculose Animal. Ministério da Agricultura Pecuária e Abastecimento. <www.agricultura.gov.br> Acesso em 18 set 2016.

BRASIL 2006. Programa Nacional de Controle e Erradicação da Brucelose e da Tuberculose Animal (PNCEBT): Manual Técnico. Ministério da Agricultura Pecuária e Abastecimento, Brasília, DF. 188p.

BRASIL 2013. IN n 50, de 24 de setembro - Altera a lista de doenças passíveis da aplicação de medidas de defesa sanitária animal e estabelece sua notificação obrigatória. Ministério da Agricultura Pecuária e Abastecimento. <www.agricultura.gov.br> Acesso em 16 set 2016.

BRASIL 2016. IN n 19, de 10 de outubro - Estabelece o Regulamento Técnico do Programa Nacional de Controle e Erradicação da Brucelose e da Tuberculose Animal - PNCEBT e a Classificação das Unidades da Federação de acordo com o grau de risco para as doenças brucelose e tuberculose. Ministério da Agricultura Pecuária e Abastecimento. $<$ www.agricultura.gov.br> Acesso em 1nov 2016.

CHATE, S.C., DIAS, R.A., AMAKU, M., et al.Situaçãoepidemiológica da brucelose bovina no Estado doMato Grosso do Sul. Arq. Bras. Med. Vet. Zootec., v.61, supl. 1, p.46-55, 2009.

DISTRITO FEDERAL 2015. Decreto $n^{\circ}$ 36.589, de 07 de julho -Regulamenta a Lei ${ }^{\circ} 5224$, que dispões sobre a Defesa Sanitária Animal no Distrito Federal. Secretaria de Estado da Agricultura, Abastecimento e Desenvolvimento Rural do Distrito Federal. $<$ www.agricultura.df.gov.br> Acesso em 10 set 2016.

DOHOO I., MARTIN, W., STRYHN, H. Veterinary Epidemiologic Research. Charlottetown: University of Prince Edward Island, $2^{\circ}$ ed., 2010. 865p. 
FERREIRA NETO, J.S., SILVEIRA, G.B., ROSA, B.M., et al. Analysis of 15 years of the National Program for the Control and Erradication of Animal Brucellosis and Tuberculosis, Brazil. Semina: Ciências Agrárias, v.37, n.5, Suplemento 2, p.3385-3402, 2016.

FLETCHER, R.H., FLETCHER, S.W., WAGNER, E.H. Clinical Epidemiology: the essentials. Baltimore: Williams \& Wilkins, $2^{\circ}$ ed., 1988. 246p.

GONÇALVES, V.S.P., RIBEIRO, L.A., CALDAS, R.A., etal.Situação epidemiológica da brucelose bovina no Distrito Federal. Arq.Bras. Med. Vet. Zootec.,v.61, supl. 1, p.14-18, 2009.

HOSMER,D.W., LEMESHOW, S., STURDIVANT, R.X. Applied logistic regression.New York: John Wiley \& Sons, $3^{\circ}$ ed., 2013. 528p.

IBGE 2016a. Estados@ - Distrito Federal: Sinopse do Censo Demográfico 2010. $<$ http://www.ibge.gov.br/estadosat/temas.php?sigla=df\&tema=sinopse_censodemog2010> Acesso em 16 set 2016.

IBGE 2016b. Produção da Pecuária Municipal 2015. $<$ http://cidades.ibge.gov.br/xtras/temas.php?lang=\&codmun=530010\&idtema=159\&search=d istrito-federal|brasilia|pecuaria-2015> Acesso em 06 nov 2016.

KURODA, R.B.S., NEGREIROS, R.L., OSSADA, R., et al. Method for determining bovine brucellosis vaccination coverage. Semina: Ciências Agrárias, v.37, n.5, Suplemento 2, p.3759-3766, 2016.

LEITE, B.M. Aspectos epidemiológicos e econômicos da certificação de propriedades leiteiras como livres de brucelose e tuberculose bovina. 2012. Vii, 81f., il. Dissertação (Mestrado em Saúde Animal) - Universidade de Brasília, Brasília, 2012.

MOTA, A.L.A.A., FERREIRA, F. FERREIRA NETO, J.S., et al. Large-scale study of herdlevel risk factors for bovine brucellosis in Brazil. ActaTropica, v.164, p.226-232, 2016.

NEGREIROS, R.L., DIAS, R.A., FERREIRA, F., et al.Situaçãoepidemiológica da brucelose bovina no Estado de Mato Grosso. Arq. Bras. Med. Vet. Zootec., v.61, supl. 1, p.56-65, 2009.

OLIVEIRA, L.F., DORNELES, E.M.S., MOTA, A.L.A.A., et al. Seroprevalence and risk factors for bovine brucellosis in Minas Gerais State, Brazil. Semina: Ciências Agrárias, v.37, n.5, Suplemento 2, p.3449-3466, 2016. 
ROCHA, W.V., GONÇALVES, V.S.P., COELHO, C.G.N.F.L., etal.Situaçãoepidemiológica da brucelose bovina no Estado de Goiás. Arq.Bras. Med. Vet. Zootec.,v.61, supl. 1, p.27-34, 2009.

SANTOS, R.L., MARTINS, T.M., BORGES, A.M., et al. Economic losses due to bovine brucellosis in Brazil. Pesq. Vet. Bras., 33(6), p.759-764, 2013.

VILLAR, K.S., AMAKU, M., DIAS, R.A., etal.Situaçãoepidemiológica da brucelose bovina no Estado de Rondônia. Arq. Bras. Med. Vet. Zootec., v.61, supl. 1, p.85-92, 2009. 